\title{
LA «PRESIDENCIA IMPERIAL»Y SU EVOLUCIÓN EN LA ESTRUCTURA CONSTITUCIONAL DE LOS ESTADOS UNIDOS DE AMÉRICA
}

DAVID MENDIETA

FELIPE CALDERÓN-VALENCIA 
SUMARIO

I. INTRODUCCIÓN. II. EL ESPÍRITU DE LA CONSTITUCIÓN ESTADOUNIDENSE DE 1787 EN RELACIÓN A SU ESTRUCTURA. 1. Un oxímoron: el poder más débil. 2. La separación de poderes y el sistema de frenos y contra pesos. 3. Hamilton, Madison y Marshall: defensores de la Constitución de 1787. III. LA PRESIDENCIA IMPERIAL COMO AMENAZA A LA ESTRUCTURA CONSTITUCIONAL. 1. Nacimiento de la "presidencia imperial». 2. Consolidación de la «presidencia imperial». 3. Plenitud de la «presidencia imperial». 4. Las agencias administrativas federales como instrumento de consolidación de la "presidencia imperial». 5. La «presidencia imperial» a la luz del constitucionalismo. CONCLUSIÓN. 


\title{
LA «PRESIDENCIA IMPERIAL» Y SU EVOLUCIÓN EN LA ESTRUCTURA CONSTITUCIONAL DE LOS ESTADOS UNIDOS DE AMÉRICA
}

\author{
DAVID MENDIETA ${ }^{1}$ \\ FELIPE CALDERÓN-VALENCIA ${ }^{2}$
}

\section{INTRODUCCIÓN}

El presente artículo se propone analizar el concepto de "presidencia imperial» en el marco del régimen presidencial estadounidense desde una perspectiva histórico-institucional. Dicho concepto se estudiará desde los fundamentos jus-filosóficos del constitucionalismo norteamericano y desde el devenir del gobierno presidencial, concentrándose en las órdenes ejecutivas como causa y efecto del protagonismo logrado por los Estados Unidos de América (en adelante, EUA) en el contexto internacional.

Ciertamente el predominio del ejecutivo sobre las otras ramas del poder público no es un tropismo estadounidense ${ }^{3}$, pero se hace necesario prestar más atención a este

${ }^{1}$ Profesor titular de Derecho Constitucional, Facultad de Derecho, Universidad de Medellín, Carrera 87 Nº6-65, Medellín, Colombia e-mail: davidmendietagonzalez@ hotmail.com

2 Profesor titular de Derecho Constitucional, Facultad de Derecho, Universidad de Medellín, Carrera 87 N.60-65, Medellín, Colombia e-mail: felipecalderonvalencia@gmail.com

${ }^{3}$ El ejercicio exacerbado del ejecutivo se manifiesta en varias regiones (Lavaux, Ph. (2002). Destins du présidentialisme (1st ed.) Paris, PUF, 138 pp.), pero sobre todo en América Latina; ver: Serrafero, M. D. (1991) «Presidencialismo y Reforma Política en América Latina», Revista del Centro de Estudios Constitucionales, 195(8), pp. 195-235; García, J.-R. (2014) « Presidencialismo o Poder Ejecutivo ambivalente? De la pertinencia de la noción jurídica para el estudio de los sistemas políticos de América Latina», Cuestiones constitucionales: revista mexicana de derecho constitucional, 31, pp. 58-79; pero sobre todo el gran análisis de: García Belaunde, P. (2014) «Los vaivenes del Constitucionalismo Latinoamericano en las últimas décadas», Revista de Derecho Político, 89, pp. 391-412 (ver, sobre todo: 399-407). 
caso que a otros ${ }^{4}$; las tensiones internacionales generadas por el Presidente hacen que el estudio de sus instituciones políticas sea un tema de imperativo conocimiento para todo jurista. Así, por ejemplo, es de sumo interés la manera en que desde la Casa Blanca se influencia a los demás órganos del gobierno federal, poniendo en cuestión tanto la autonomía de estos como de las agencias administrativas federales, como lo señala Vermeule ${ }^{5}$, en el llamado Administrative State ${ }^{6}$.

En 2016, luego de la elección de Donald Trump como presidente de los EUA, se hace cada vez más necesaria la reflexión teórico-retrospectiva y seria sobre la figura del Presidente en el gobierno federal por fuera del contexto estrictamente político ${ }^{7}$. El debate no puede reducirse a los comentarios promovidos por obras como Fire and Fury: Inside the Trump White House ${ }^{8}$. Por el contrario, deben analizarse los poderes y prerrogativas que manan de su autoridad, tal y como lo hacen otros investigadores en

${ }^{4}$ Si bien metodológicamente, no podemos tratar sino un tema en el mare magnum de cuestiones que toca el estudio actual del régimen presidencial, es importante resaltar que su declinación, el presidencialismo, es tal vez un destino para los países donde el régimen político se inclina demasiado en el poder ejecutivo. En este tópico — que podemos únicamente referenciar- cabe destacar que la institución presidencial está aferrada al imperio del derecho o a las vías democráticas; ver: Olivares, N. E. (2015) «Presidencialismo populista vs. Presidencialismo deliberativo», Estudios: Centro d Estudios Avanzados, 33, pp. 31-48; anotamos que si bien el régimen presidencial es diferente del presidencialista, sus fuentes de dinámica se encuentran en América Latina, cuyos devenires atraen a la prensa, no solamente en lo propio de los EUA — caso que motiva este artículo — sino también otros como el de Cuba, que también es de plena actualidad, ver: Press, T. A. (2018) «Raul Castro Acts Like He’s Retiring Though Future Unclear», The New Yourk Times (consultado en: https://www.nytimes.com/ aponline/2018/04/20/world/americas/ap-cb-cuba-raul-castro.html)

5 Vermeule, A. (2016). Law's Abnegation. From Law's Empire to the Administrative State (1st ed.), Cambridge, Harvard University Press.

${ }^{6}$ Este concepto se popularizó con el desarrollo de la Public Administration. Si bien este era, tradicionalmente, más cercanos al Civil Law francés —aunque también de la mano del local gouvernment inglés, estudiado por otros países de la Europa continental (ver: Vandelli, L. (2012) «Local government in Italy», in Moreno, A.-M. (ed.) Local government in the Member States of the European Union: a comparative legal perspective (1st ed), Madrid: INAP, pp. 339-364), fueron tomando fuerza en los EUA con las investigaciones de Dwight Waldo y otros. Además, hay que agregar que la constitucionalización del concepto de administración pública como fundamento práctico de toda organización estatal (federal o centralista) lleva a hoy en día a entenderlo como inherente a las funciones presidenciales: «Contemporary presidents have increased the administrative capabilities of their office in two important ways. First, they have sought to increase White House control over the federal bureaucracy. Second, they have expanded the role of executive orders and other instruments of direct presidential governance. Taken together, these components of administrative strategy have given presidents a capacity to achieve their programmatic and policy goals even when they are unable to secure congressional approval.» (Vermeule, A. (2013) The Constitution of Risk. New York: Cambridge University Press, p. 163); al respect ver igualmente: Lowi, T. J., Ginsberg, B. and Ansolabehere, S. (2017) American Gouvernment. Power and Purpose (14th ed), New York: W.W. Norton \& Company, Inc., pp. 290-299; Waldo, D. (1948) The Administrative State. A study of the Political Theory of American Public Administration. 1st edn. New York: Ronald Press Company, 227 pp.

7 Bitecofer, R. (2018) The Unprecedented 2016 Presidential Election. Cham: Palgrave Macmillan. «https://doi.org/10.1007/978-3-319-61976-7.»

8 Wolff, M. (2018). Fire and Fury: Inside the Trump White House (1st ed.), London, Henry Holt and Co. 
contextos como política externa ${ }^{9}$ e interna — donde sobresale la relación con las otras ramas del poder público ${ }^{10}$.

Previo a todo análisis de fondo, puede afirmarse que el poder ejecutivo de la Constitución estadounidense de 1787 está regulado en el Artículo II. Las cuatro secciones de esta norma son el resultado de una serie evoluciones. En primer lugar, las primeras se dieron en el marco de la convención constitucional que pretendía «modificar» la Constitución de la Confederación (1776); se recuerda la pugna entre quienes eran favorables a un gobierno federal ${ }^{11}$ y los anti-federalistas ${ }^{12}$. Llama la atención que el mayor temor era que se limitaran la autonomía y libertades de los Estados confederados en favor de un gobierno que pudiera considerarse nacional ${ }^{13}$; si la independencia había sido detonada por la violación del derecho natural de decidir sobre los tributos inscrito con fuego en la Constitución no escrita de la Commonwealth inglesa ${ }^{14}$, no podía esperarse que se viera con buenos ojos un gobierno central «enérgico» ${ }^{15}$. En segundo lugar, los cambios sufridos por el Artículo II son fruto de la práctica y de su aplicación durante los siglos XIX, Xx y lo que va del XXI.

La adversidad a la pérdida de la autonomía forzó la imposición de dos tipos de límites al Presidente del gobierno federal: políticos y jurídicos, a través de la Constitución y de la ley (e.g. el Administrative Procedural Act o APA de 1946 ${ }^{16}$ ). Entre los primeros, figuran el gobierno representativo y alternancia en el poder; entre los segundos, todos los mecanismos derivados del sistema de frenos y contrapesos (ckecks

9 Starr-Deelen, D. G. (2018). Counter-terrorism from the Obama administration to President Trump: caught in the fait accompli war (1st ed.), Cham, Palgrave Macmillan; Feldman, S. M. (2017). The new Roberts court, Donald Trump, and our failing constitution, Cham, Palgrave Macmillan, pp. 159-61.

${ }_{10}$ Feldman, S. M. (2017). The new Roberts court, Donald Trump, and our failing constitution, Cham, Palgrave Macmillan; McMahon, K. J. (2007). «Presidents, Political Regimes, and Contentious Supreme Court Nominations: A Historical Institutional Model». Law E Social Inquiry, 32(4), 919-954. https:// doi.org/10.1111/j.1747-4469.2007.00083.x

${ }^{11}$ Hamilton, A., Madison, J., \& Jay, J. (2008). The Federalist Papers. (L. Goldman, Ed.), New York, Oxford University Press.

12 Ketcham, R. (Ed.). (2003). The Anti-Federalist Papers and The Constitutional Convention Debates, Turtleback School \& Library Binding Edition, pp. 16-20.

13 Fue tras un intenso debate que los Anti-Federalistas deciden aceptar el gobierno federal y la Constitución. A cambio exigieron un Bill of Rights para tener garantías y así firmar el «contrato social» ver: Zoller, E. (2013). Introduction au droit public (2nd ed.), Paris, Dalloz, pp. $127-128$.

${ }^{14}$ Brennan, G. (1987). El poder fiscal. Fundamentos analíticos de una constitución fiscal, Madrid, Unión Ed. S.A.

${ }^{15}$ El término energetic y su odiosa relación con el Gobierno Federal, fue criticada por los anti-federalistas. En octubre de 1787 los papers de John De Witt atacaron la creación de un ejecutivo con poderes inmensos, por miedo a que desdibujara las libertades individuales, ver: Ketcham, R. (Ed.). (2003), The Anti-Federalist Papers and The Constitutional Convention Debates, Turtleback School \& Library Binding Edition, pp. 189-198.

${ }^{16}$ Este es el estatuto del gobierno federal. Este puede encontrarse como Pub.L.79-404 (60 Stat. 237) y en vigor desde el 11 de junio de 1946. Además, hace parte del Código de los EUA o U.S. Code (ver el siguiente vínculo: https://www.law.cornell.edu/uscode/text/5). 
and balances), refuerzo del principio de la separación de poderes, popularizada por $D e$ L'esprit des $\operatorname{lois}^{17}$. Todo esto para mantener a raya al déspota, para menguar la fuerza del gobierno arbitrario.

Entendiendo este contexto, es difícil imaginar cómo el unilateralismo del Presidente $^{18}$ ha tomado fuerza y forma en la «presidencia imperial», pero es igualmente preocupante ver como personas como Donald Trump toman las riendas del gobierno de un país tan poderoso. ¿Qué tipo de límites, institucionales y reales tiene la Presidencia de los EUA? Responder a este tipo de dudas requiere de un plan que evidencie la conexión entre: (II) pasado de la estructura constitucional y (III) porvenir de una patología del ejecutivo federal.

\section{EL ESPÍRITU DE LA CONSTITUCIÓN ESTADOUNIDENSE DE 1787 EN RELACIÓN A SU ESTRUCTURA}

El constitucionalismo es reciente, fundado en la idea norteamericana de lo que es una Constitución. Su conexión con el English Common Law transmitió su uso como límite efectivo al poder gracias al control a los actos del Parlamento y del rey ${ }^{19}$. El llamado Dr. Boham's case de $1610^{20}$, del juez Coke, es un ejemplo palpable de las primeras manifestaciones garantistas donde el poder de una ley es frenado por considerarse contrario a normas de un rango superior ${ }^{21}$. En efecto, muchos autores ingleses influirían en la idea norteamericana de Constitución, como Harrington y su propuesta de romper con el pasado, superar el viejo régimen y el gobierno moderado ${ }^{22}$. Por su parte, de Bolingbroke se tomó el gobierno de la Constitución, donde el primero

17 Montesquieu, C.-L. de S. (1951). Tome II. (R. Caillois, Ed.), Oeuvres complètes, Paris, Gallimard.

18 Rudalevige, A. (2012). «The Contemporary Presidency: Executive Orders and Presidential Unilateralism». Presidential Studies Quarterly, 42(1), 138-160. https://doi.org/10.1111/j.1741-5705.2012.03945.x

19 En el año XII (d.C), Bracton ya había transmitido la noción de supralegalidad. Esta cimentaba el Commonwealth, tal y como consta en obras como De Legibus Et Consuetudinibus Anglice (ver: Harvard Law School Library. (2003), Bracton Online search page, Retrieved January 16, 2018, from http://bracton.law.harvard.edu/Common/SearchPage.htm); Fioravanti, M. (2001). Constitución: de la antigüedad a nuestros dias, Madrid, Trotta, p. 170.

${ }^{20}$ Helmholz, R. H. (2009). «Bonham's Case, Judicial Review, and the Law of Nature». Journal of Legal Analysis, 1(1), 325-354. https://doi.org/10.4159/jla.v1i1.5

${ }^{21}$ Esta decisión se enmarca en una lucha contra la dinastía de los Estuardo; James I pretendía imponer una lógica católica del poder en un país profundamente protestante. Coke declaró que ningún acto del Parlamento contrario a la razón y al Common Law podía ser aplicado; ver: Harvard Law School Library. (2003). Bracton Online search page. Retrieved January 16, 2018, from http:// bracton.law.harvard.edu/Common/SearchPage.htm; Kantorowicz, E. H. (1985). The King's Two Bodies. A Study in Medieval Political Theory, Princeton, Princeton University Press; Smith, D. C. (2014). Sir Edward Coke and the reformation of the laws: religion, politics and jurisprudence, 1578-1616, Cambridge, Cambridge University Press.

22 James Harrington, «The Commonwealth of Oceana» and «A System of Politics», ed. by J. G. A. Pocock (Cambridge: Cambridge University Press, 1992), pp. 267-93. 
era bueno si obraba conforme a esta segunda ${ }^{23}$. De John Locke, los estadounidenses conservaron los poderes moderados; herederos del principio de King in Parliament, el poder ejecutivo, por ejemplo, no fue concebido como todo poderoso. En suma, la noción de Higher Law - presente por igual en Blackstone ${ }^{24}$ y Dicey ${ }^{25}$ - toma vida propia en EUA con el constitucionalismo escrito. Esta idea simple daba cuerpo y forma a la catedral gótica que era tradición jurídica anglosajona ${ }^{26}$ permitiendo diferenciar los cimientos de estructuras superficiales y propiciando el advenimiento de la supremacía constitucional; los norteamericanos lograron separar, conceptualmente, la norma superior de los mandatos reales y de los actos del poder legislativo ${ }^{27}$.

Con independencia de los EUA nace la desconfianza del poder, inclusive del poder institucionalizado ${ }^{28}$. A partir de 1776, la Constitución Política comenzó a ser vista como un compendio escrito de derechos y de principios que todo pueblo libre estaba en capacidad de darse. Pero esta estaba avocada a convertirse en un límite al poder estatal $^{29}$. Ligado a esto, se crean las bases del derecho a reclamar el respeto de dicha limitación, cláusula esencial de un «contrato social». En este momento, cabe elevarse la duda sobre quién debe ser, entonces, el encargado de hacer tangibles estos rasgos de la cultura constitucional estadounidense. Dar una respuesta, requiere estudiar (1) algunos fundamentos y (2) ciertos autores tutelares para luego estudiar (3) la transmisión de su legado de la Constitución de 1787.

\section{Un oximoron: el poder más débil}

«De los tres poderes que hemos hecho mención, el de juzgar es casi nulo»: paráfrasis de Montesquieu, esta frase permite identificar cómo este referente aux Lumières no veía en los jueces un verdadero límite a los poderes ejecutivo y legislativo ${ }^{30}$. Pese a que

${ }^{23}$ Henry Bolingbroke, Bolingbroke: Political Writings, ed. by David Armitage (Cambridge: Cambridge University Press, 1997), pp. 217-94.

${ }^{24}$ Blackstone, W. (2016). Commentaries on the Laws of England. (D. (Ed's I. N. and T. A. Lemmings \& W. (General E. I. and E. C. and P. Prest, Eds.), I (Of the Rights of Persons), Oxford, Oxford University Press.

${ }_{25}$ Dicey, A. V. (1982). Introduction to the study of the law of the constitution. (M. E. Roger, Ed.), Indianapolis, Liberty Fund.

26 Whittaker, S. (2008). «El Precedente en el Derecho Inglés: una visión desde la Ciudadela». Revista Chilena de Derecho, 35(1), 37-83. https://doi.org/10.4067/S0718-34372008000100003

${ }^{27}$ García de Enterría, E. (2006). La Constitución como norma y el Tribunal Constitucional (4th ed.), Madrid, Editorial Civitas.

${ }^{28}$ Bailyn, Ideological Origins of the American Revolution (Cambridge: The Belknap Press, 1992), pp. 94-229.

${ }^{29}$ Regla, J. A., Atienza, M., Barberis, M., Comanducci, P., Chiassoni, P., Ferrajoli, L., ... Ugarte, P. S. (2012). Un debate sobre el constitucionalismo. (L. Ferrajoli, Ed.), Madrid, Marcial Pons.

${ }^{30}$ Binoche, B. (2015). Introduction à De l'esprit des lois de Montesquieu (2nd ed.), Paris, Publications de la Sorbonne, pp. 152-154; Montesquieu, B. C. L. de S. (2015). Del espiritu de las leyes. (D. Moreno, Ed.) (20th ed.), Mexico, Porrua, p. 151. 
hoy en día ciertas investigaciones evidencien la existencia de un «Judicial Revieuw before Marbury» [vs Madison] ${ }^{31}$, no deja de sorprender que esta influencia del republicanismo francés del siglo XVIII sobre el Judicial Department estadounidense propiciara la Judicial Review (control de constitucionalidad de la ley), aunque no haya sido con el fallo Marbury vs. Madison ${ }^{32}$. La Corte del Chief Justice Marshall ayudó a convertir al poder judicial en un tercer poder, o un contrapoder magister dixit ${ }^{33}$. Dicha decisión de la Suprema Corte de Justicia de EUA no fue comprendida al comienzo y sus consecuencias fueron vistas por ciertos teóricos como una amenaza a la separación de poderes; Éduard Lambert pudo hablar de este fenómeno como «gobierno de los jueces» ${ }^{34}$.

Fuera del republicanismo y su propuesta de gobierno moderado ${ }^{35}$, el liberalismo político fue otro fundamento del constitucionalismo estadounidense. Los matices adquiridos por principios tradicionales como la separación de poderes ${ }^{36}$, nacen de la práctica en una sociedad diferente ${ }^{37}$, que construyó en 1787 una Constitución que institucionaliza la libertad a través de la desconfianza del poder, incluso del legislativo $^{38}$. Esta actitud reposa en dos aspectos, uno histórico y otro puramente normativo.

31 Treanor, W. M. (2005). «Judicial Review Before Marbury». Standford Law Review, 58(2), 455562. Retrieved from http://scholarship.law.georgetown.edu/facpub/1033

32 Turner, K. (1960). «The Midnight Judges». Penn Law Review, 4(109), 1961, 494-523. http:// scholarship.law.upenn.edu/cgi/viewcontent.cgi? article $=6949 \&$ context = penn_law_review; U.S. Supreme Court. Marbury v. Madison, 5 U.S. 137 (1803).

33 Zoller, E. (2010) «Le juge constitutionnel est-il un contre-pouvoir? Table ronde du Centre français de droit comparé (Paris, 21 juin 2010)», Revue internationale de droit comparé, 62(3), pp. 788-812 «doi: 10.3406/ridc.2010.19967»

34 Parece normal que Lambert viera burlados dichos fundamentos sin reflexionar mucho sobre la normalidad para cada país, pues su tradición constitucional era diferente (ver: Calderon Valencia, F. (2016). Le contrôle a posteriori de la constitutionnalité des lois en droit français et colombien, éléments de comprébension d'une culture constitutionnelle, Université Pantéon-Assas (Paris II). Retrieved from https://www.theses. fr/194933792, pp. 252-263). La crítica de Lambert es dirigida desde el republicanismo, inherente a la tradición constitucional francesa, incapaz de ver que no fuera el legislativo quien controle la ley. El legicentrismo propio de la cultura constitucional de la Europa continental es un lugar común en el derecho del siglo XIX, encarnado por la idea de ver la ley como la expression de la volonté générale — según la fórmula usada por Rousseau en el Contrato Social— se pueden garantizar las libertades públicas. Esto también estaba presente en la Constitución francesa de 1791. El artículo 3. ${ }^{\circ}$ de su Capítulo V no dejaba dudas sobre el status del poder judicial (Les tribunaux ne peuvent, ni s'immiscer dans l'exercice du Pouvoir législatif, ou suspendre l'exécution des lois, ni entreprendre sur les fonctions administratives, ou citer devant eux les administrateurs pour raison de leurs fonctions.); ver: Wilson, W. (1885). Congressional government : a study in American politics (M. and C. Houghton, Ed.), Boston, The Riverside Press, pp. 1-50; Lambert, E. (2010). El gobierno de los jueces y la lucha contra la legislación social en los Estados Unidos: la experiencia americana del control judicial de la constitucionalidad de las leyes, Madrid, Tecnos, pp. 11-83.

35 Montesquieu, B. C. L. de S. (2015). Del espiritu de las leyes. (D. Moreno, Ed.) (20th ed.), Mexico, Porrua, pp. 67-87.

36 Troper, M. (1980). La separation des pouvoirs et l'bistoire constitutionnelle francaise (1st ed.), Paris, LGDJ.

37 Tocqueville, A. de. (2007). La democracia en América, Madrir, Ediciones AKAL.

38 Wilson, W. (1885). Congressional government : a study in American politics. (M. and C. Houghton, Ed.), Boston, The Riverside Press. 
Primero, recuérdese que el Parlamento inglés aprueba el Stamp Act en $1765^{39} \mathrm{e}$ impone un tributo no consentido a sus colonias en América ${ }^{40}$, resquebrajándose las relaciones con la metrópoli. Luego vendría la reacción de la asamblea de Virginia ${ }^{41}$, protesta que fue rápidamente sofocada con el Declaratory Act de $1766^{42}$ que permitía a la Corona imponer tributos en suspensión de las normas fundamentales ${ }^{43}$. Sobrevinieron, entonces, la guerra y la independencia.

Segundo, tras haber aprendido que el Parlamento inglés era capaz de suspender los efectos de su propia ley fundamental, los Padres Fundadores de 1787 conciben una Constitución escrita dedicando nueve secciones en el Artículo I a limitar el poder del legislador, frente cuatro dedicados al ejecutivo en el Artículo II y tres al judicial en el Artículo III ${ }^{44}$. Herederos del Common Law ${ }^{45}$, la Convención Constitucional de Filadelfia de 1787 defendió una aristocracia judicial en el Artículo III, encargándole la salvaguardar el derecho a través del precedente judicial como la forma «To avoid an arbitrary discretion in the courts, it is indispensable that they should be bound down by strict rules and precedents» (Paper 78) ${ }^{46}$.

Ahora bien, en cuento a la cuestión central del presente texto, la Presidencia es limitada en lo necesario por la Constitución; recordemos el precitado Paper: «The Executive not only dispenses the honors, but holds the sword of the community». Primero, porque este poder ya estaría, de sí, contrarrestado por la competencia de la ley; y, segundo, porque los reunidos en Pennsylvania entre mayo y septiembre de 1787 creyeron que una vez electo el primer presidente este se encargaría de darle forma y contenido a la institución ${ }^{47}$. Sin embargo, para el simple observador resulta un tanto extraño que se le haya dado tal preponderancia a lo personal sobre lo institu-

39 Stamp Act (trans. from the original). (1765) (consultado en: http://www.stamp-act-history.com/ stamp-act/stamp-act-of-1765-original-text/, 22 abril de 2018); ver igualmente: Morgan, E. S., \& Morgan, H. M. (1953). The Stamp act crisis. Prologue to revolution, Williamburg, University of North Carolina Press.

40 Elster, J. (2018). «Collective Action in America Before 1787», en Morality, Governance, and Social Institutions, Cham, Springer International Publishing, 157-195, https://doi.org/10.1007/978-3-31961070-2_7

41 Fioravanti, M. (2001). Constitución: de la antigüedad a nuestros días, Madrid, Trotta, p. 170.

42 Declaratory Act (trans. from the original). (1766) (consultado en: http://www.stamp-act-history. com/documents/1766-declaratory-act-original-text/, 22 abril de 2018).

${ }^{43}$ Racheter, D. P., \& Wagner, R. E. (2002). «The Constitutional Framework for Democratic Taxation», en Politics, Taxation, and the Rule of Law, Boston, MA, Springer US, 1-7. «https://doi. org/10.1007/978-1-4615-1069-7_1»

44 Constitución de los EEUU (1787).

45 Mendieta González, D., Peláez Arango, F., Restrepo Tamayo, J. F., Ferrer Murillo, J. M., Toledo Perdomo, J. F., Amaya Castrillón, J. C., ... Gallo Callejas, M. A. (2012). Derecho constitucional general. (C. M. Molina Betancur, Ed.) (4th ed.), Medellín, Sello editorial Universidad de Medellín.

${ }^{46}$ Hamilton, A., Madison, J., \& Jay, J. (2008). The Federalist Papers. (L. Goldman, Ed.), New York, Oxford University Press, p. 385.

47 Ortiz JR, D. (2004). «La Presidencia de los Estados Unidos ¿un modelo de poder ejecutivo?». Espacio Tiempo Y Forma. Serie V, Historia Contemporánea, (16), 13-66. https://doi.org/10.5944/etfv.16.2004.3084 
cional $^{48}$. De ahí que sea necesario revisar ciertos aspectos de las bases filosóficas del principio de la separación de poderes.

\section{La separación de poderes y el sistema de frenos y contra pesos}

Los Padres Fundadores sustituyeron la Confederación de 1776 para imponer gobierno moderado y conjurar la anarquía que trajo la independencia ${ }^{49}$, subyugando el poder político a un sistema que: garantizara las libertades con las primeras 14 enmiendas constitucionales y facilitara la alternancia del poder con las restricciones de una rama frente a la otra ${ }^{50}$. Thomas Jefferson le llamaba a esto la guerra de pode$\mathrm{res}^{51}$ que propicia la combinación entre el principio de separación de poderes y el sistema de checks and balances. Ambos se diferencian no solo conceptualmente, sino en sentido práctico. Desde un punto de vista descriptivo, la separación de poderes demarca claramente el texto constitucional. La influencia de Montesquieu está presente en sus tres primeros artículos, al separar al legislativo, al ejecutivo y al judicial. Desde lo operativo, el poder judicial está encargado de anteponer el derecho a toda acción de los otros dos poderes públicos ${ }^{52}$.

Buena parte de la desconfianza hacia el poder político recae sobre el legislativo, pero el mismo checks and balances produce que la Presidencia esté limitada por la ley: el Artículo I, Sección 1 expresa que «Todos los poderes legislativos otorgados por esta Constitución residirán en un Congreso de los Estados Unidos...». El término «Todos» es categórico. No se contempló, entonces, que el Presidente expidiera normas con el mismo valor de la ley. Ni siquiera se contemplan los Estados de Excepción; el ejecutivo no legisla cuando el orden democrático se ve amenazado, tal y como es la costumbre en los regímenes presidencialistas ${ }^{53}$.

48 Esta es la cita textual de la obra referenciada: «The ingredients which constitute energy in the Executive are, first, unity; secondly, duration; thirdly, an adequate provision for its support; fourthly, competent powers. / The ingredients which constitute safety in the republican sense are, first, a due dependence on the people, secondly, a due responsibility.» Hamilton, A., Madison, J., \& Jay, J. (2008). The Federalist Papers. (L. Goldman, Ed.), New York, Oxford University Press, p. 343

49 Ver: Ketcham, R. (Ed.). (2003). The Anti-Federalist Papers and The Constitutional Convention Debates, Turtleback School \& Library Binding Edition.

50 Zoller, E. (1999b). Droit constitutionnel (2nd ed.), Paris, PUF.

51 Erin Ryan, «Federalism and the Tug of War Within: Seeking Checks and Balance in the Interjurisdictional», Maryland Law Review, 66.3 (2007), 503-667 «https://doi.org/doi:10.2139/ ssrn.1350008»

52 Shapiro, M. (1993). «Revisión Judicial a priori y a posteriori: los modelos norteamericano y europeo». Revista Chilena de Derecho - XXIV Jornadas Chilenas de Derecho Público: Tomo 1 (Mayo-Diciembre 1993), 20(2/3), 475-479. https://doi.org/10.2307/41888186

53 Valadés, D. (1982). «El Presidencialismo Latinoaméricano en el siglo XIX». Boletín Mexicano de Derecho Comparado, 44, 613-626. https://doi.org/http://dx.doi.org/10.22201/iij.24484873e.1982.44 Tobon, M. y Mendieta, D. (2017). «Los estados de excepción en el régimen constitucional colombiano». Opinion Jurídica, 31, 67-88. https://doi.org/10.22395/ojum.v16n31a3 
No obstante, el Presidente puede valerse de las órdenes ejecutivas con fundamento en la sección 2 del Artículo II de la Constitución. Las órdenes ejecutivas pueden definirse como una norma adoptada por el Presidente cuya fuerza es igual a la de la ley, pero cuyo objeto son las autoridades de su propia rama ${ }^{54}$. Esto afecta la rama legislativa porque mediante estas órdenes el Presidente escapa a los límites fijados por la sección 1 del Artículo I. Al fijar directrices que en sustancia son políticas (sustantive policy) el Presidente puede, por ejemplo, mantener sus coaliciones de gobierno, reforzar el control que ejerce sus Government Agencies ${ }^{55}$ — como la CCS o la FSAsobre otros organismos ${ }^{56}$. No obstante, las órdenes ejecutivas son controladas a través de la Judicial Review y por el Congreso (Artículo I, Sección 8).

Al tener fuerza de ley, las órdenes ejecutivas sustituyen al Congreso en su competencia legislativa. Según el Congressional Research Service ${ }^{57}$, la naturaleza jurídica de las órdenes ejecutivas es difícilmente determinable, pues son normas escritas que «simplemente» se derivan del Artículo II de la Constitución ${ }^{58}$, en especial de la Sección 3. a —igualmente, la Cláusula 5. a - porque liga los poderes implícitos del Presidente con la capacidad de hacer cumplir «fielmente las leyes». Es decir, la capacidad de expedir órdenes ejecutivas no es una competencia constitucional, sino una prerrogativa adquirida con la práctica, el paso del tiempo y las luchas políticas.

En efecto, los Funding Fathers no promovieron un Presidente legislador, pero tampoco cerraron esa posibilidad, dejándola a merced de la contumacia de los otros poderes. A finales del siglo XVIII, la amenaza militar externa latente pudo haber sido razón suficiente para no proscribir un Presidente capaz de liderar la defensa y preservar la libertad 59 . En la actualidad, este argumento parece estar ligado a que luego de acabada la Segunda Guerra Mundial, ninguna declaración oficial de guerra ha sido

${ }^{54}$ Mayer, K. R. (1999). «Executive Orders and Presidential Power». The Journal of Politics, 61(2), 445-466. https://doi.org/10.2307/2647511

55 Peters, B. G. (2012). The United States of America. In Government Agencies (pp. 69-76), London, Palgrave Macmillan UK. https://doi.org/10.1057/9780230359512_7

56 Mayer, K. R. (1999). «Executive Orders and Presidential Power». The Journal of Politics, 61(2), 445-466. https://doi.org/10.2307/2647511

57 Chu, V. S., \& Garvey, T. (2014). Executive Orders: Issuance, Modification, and Revocation, Washington. Retrieved from https://fas.org/sgp/crs/misc/RS20846.pdf

58 «Just as there is no definition of executive orders... in the U.S. Constitution, there is, likewise, no specific provision authorizing their issuance. As such, authority for the execution and implementation of these written instruments stems from implied constitutional and statutory authority. In the constitutional context, presidential power is derived from Article II of the U.S. Constitution, which states that «the executive power shall be vested in a President of the United States,» that «the President shall be Commander in Chief of the Army and Navy of the United States,» and that the President «shall take Care that the Laws be faithfully executed.» The President's power to issue these directives may also derive from express or implied statutory authority.» Chu, V. S., \& Garvey, T. (2014). Executive Orders: Issuance, Modification, and Revocation, Washington, p. 2 (consultado en: https://fas.org/sgp/crs/misc/ RS20846.pdf, 22 de abril de 2018).

59 Elisabeth Zoller, Introduction Au Droit Public, 2nd edn (Paris: Dalloz, 2013). 
autorizada por el Congreso a petición del Presidente ${ }^{60}$ con fundamento en el Artículo I, sino que las acciones militares en el extranjero se llevan a cabo con fundamento en el Artículo II, Sección 3, Cláusula 1, donde hay que distinguir, conceptualmente, entre guerra y acción militar.

En el siglo xx, bajo el pretexto de conservar la libertad in abstracto, los poderes de guerra del Presidente permitieron la invasión a Vietnam, así como otras actividades bélicas en Medio Oriente y Centro América (infra 2.). Este tipo de acciones aumentan o reducen la popularidad del jefe de Estado, pero objetivamente se corre el riesgo de afectar el equilibro de poderes. Ciertamente, la apropiación sistemática de competencias por parte del Presidente acrecienta su protagonismo, pero enrarecen el sentido del sistema de frenos y contrapesos. La hipertrofia del Presidente como patología constitucional hace posible la «presidencia imperial» ${ }^{61}$ y caer en el autoritarismo no era el deseo de los Framers y para demostrarlo veamos las bases filosóficas de la federación estadounidense.

\section{Hamilton, Madison y Marshall: defensores de la Constitución de 1787}

Sabemos que Alexander Hamilton es un adalid de la eficacia de la supremacía constitucional. El éxito de este concepto se debe a aquello que los juristas del siglo XIX llamaban código constitucional ${ }^{62}$, cuestión un tanto ajena al Common Law del siglo XVIII ${ }^{63}$. Pero esto es solo filosofía. El pragmatismo de los Padres Fundadores tiene efecto en la segunda parte del Artículo VI de la Constitución de 1787 transforma en norma las posiciones filosóficas. Por su parte - e inmerso en el mismo pragmatismoel Artículo III, Sección 1, consagra en la Corte Suprema y los tribunales el poder de «decir el derecho» en general e interpretar la ley en particular; si en el gobierno federal los jueces tienen estas facultades, ¿cómo entender, entonces, que su función sea vigilar a los otros dos poderes para que cumplieran estrictamente la Constitución?

Una pista para responder este interrogante está en las palabras de Hamilton cuando propone que está en los jueces «La posibilidad... de inaplicar normas en aquellos casos en los que contradicen la Constitución» ${ }^{64}$. A esto se agrega su moder-

${ }^{60}$ Ortiz JR, D. (2004). «La Presidencia de los Estados Unidos ¿un modelo de poder ejecutivo?». Espacio Tiempo Y Forma. Serie V, Historia Contemporánea, (16), 13-66 «https://doi.org/10.5944/ etfv.16.2004.3084»

${ }^{61}$ Bacevich, A. J. (2008). The Limits of Power: The End of American Exceptionalism, New York, Metropolitan Books Henry Holt and Company.

${ }^{62}$ García de Enterría, E. (2006). La Constitución como norma y el Tribunal Constitucional (4th ed.), Madrid, Editorial Civitas.

63 Blick, A. (2016). The codes of the Constitution, Oxford, Hart publishing; Keating, M. \& Laforest, G. (2018). «Federalism and Devolution: The UK and Canada», en Constitutional Politics and the Territorial Question in Canada and the United Kingdom, Cham, Springer International Publishing, 1-18 «https://doi.org/10.1007/978-3-319-58074-6_"

${ }^{64}$ Hamilton, Madison, and Jay, p. 382. 
na visión de la «ley fundamental». La percibía no solo como una norma especial, sino simplemente una norma, y como tal debía ser aplicada por los jueces ${ }^{65}$. Esta es, justamente, la quintaesencia de la teoría de la Constitución normativa: dicha norma no es un fetiche místico del orden del Estado ${ }^{66}$ sino simplemente una norma; es decir, la Constitución debe aplicarse igual que se aplica cualquier ley. Sin embargo, afirma Hamilton estas dos se diferencian cuando de un conflicto entre ambas, debe salir a flote el carácter especial de la primera: su supremacía extraída de un proceso constituyente. A este razonamiento hay que agregar la experiencia de las trece colonias con el Declaratory Act; el Parlamento desconoció, sin mayores consecuencias, las leyes fundamentales con el Declaratory Act de 1766, que era ley ordinaria ${ }^{67}$.

Ahora bien, Hamilton no proponía que el poder judicial fuera más importante que los otros departamentos del gobierno federal. Punto de vista secundado por Madison, el juez debía salvaguardar, de un lado, la integridad de un texto concebido por el Pueblo soberano y, por otro lado, el juez debía proteger los derechos y libertades ante los designios de la rama ejecutiva ${ }^{68}$. En efecto, Hamilton reafirma la validez como fundamento lógico del federalismo y las pruebas están en el Paper 78 del Federalista $^{69}$. A lo anterior agregamos que la compleja estructura de la Constitución de 1787 puede protegerse tanto en su parte orgánica como en su parte dogmática como lo muestra la decisión de la Corte Suprema McCulloch vs. Maryland-y el Bill of Rights adoptado en diciembre de $1791^{70}$.

${ }^{65}$ Hamilton, Madison, and Jay, p. 381.

${ }^{66}$ Zoller, E. (2013). Introduction au droit public (2nd ed.), Paris, Dalloz.

${ }^{67}$ En definitiva, el fondo del razonamiento de Hamilton es similar al que rigió las acciones de Coke, pues también distinguió entre dos cosas diferentes: las pretensiones perecederas de quien solo gobierna portando la corona y los designios superiores encarnados en la corona misma por el derecho como construcción histórica y tradición. Esto que Kantorowicz expresa en su teoría de los cuerpos del rey, se aplica al caso estadounidense al decir que la voluntad del pueblo encarnada en la Constitución debe estar por fuera del alcance del gobernante de turno, fenómeno cuya extrapolación se ve en las entrenchment clauses; ver: Kantorowicz, E. H. (1985). The King's Two Bodies. A Study in Medieval Political Theory, Princeton, Princeton University Press.

${ }^{68}$ Madison, J. (1953). The complete Madison: his basic writings (Saul Kussi), New York, Harper \& Brothers.

${ }^{69}$ Hamilton, Madison, and Jay, pp. 379-85.

${ }^{70} \mathrm{Y}$ es justamente este último punto el que hay que resaltar. Aquellas 12 enmiendas constitucionales propuestas en 1789 encontraron un respaldo filosófico en el pensamiento de Hamilton, pues a sus ojos era el juez quien debería garantizar el respeto de los derechos. Esto garantizaba, igualmente, el respeto de las minorías. Naturalmente, estas podían ser religiosas y políticas, pues como ya se advirtió, la opresión podía venir de las mayorías que se imponían con sus leyes. Por ende, el juez debía ser independiente. De ahí que Hamilton no escatimara en imaginar otros medios para limitar los poderes federales. Establecer un periodo fijo para el mandato del Presidente y para los miembros de las cámaras, o bien el juicio de Impeachment (ver: Paper 65, Hamilton, A., Madison, J., \& Jay, J. (2008). The Federalist Papers. (L. Goldman, Ed.), New York, Oxford University Press, pp. 321-325) era compensado con la elección vitalicia de los miembros de la Corte Suprema de Justicia (ver: Paper 78, Hamilton, A., Madison, J., \& Jay, J. (2008). The Federalist Papers. (L. Goldman, Ed.), New York, Oxford University Press, pp. 379-385. 
A lo anterior debemos agregar que — recién constituida la Unión — ya se utilizaba la Judicial Review ${ }^{71}$. Este es el gran legado de Hamilton fue la Case or Controversy Clause del Artículo III, Sección 2. Como prueba mencionemos dos casos. En 1792, en el Hayburn's Case ${ }^{72}$, la Corte Suprema contempló la posibilidad de conocer sobre un mandamus de inconstitucionalidad del Invalid Pensions Act del Congreso ${ }^{73}$. El segundo caso es la decisión Cooper vs. Telfair ${ }^{74}$. La Corte estableció que los dos departamentos del gobierno federal no podían condicionar bajo ningún acto o norma la actividad del poder judicial ${ }^{75}$. A pesar de que solamente se mencionarán los dos casos precitados, no puede dejar de mencionarse el caso Hylton vs. United States ${ }^{76}$ donde la Corte se pronunció a favor de la constitucionalidad de la ley ante ella sometida, aunque eludiendo pronunciarse ${ }^{77}$.

La famosa decisión Marbury vs. Madison ${ }^{78}$ es recordada como la primera vez que una Constitución Política sirve de racero a los actos del poder ${ }^{79}$. En efecto, el mejor

71 Treanor, W. M. (2005). «Judicial Review Before Marbury». Standford Law Review, 58(2), 455562. Retrieved from http://scholarship.law.georgetown.edu/facpub/1033

${ }^{72}$ U.S. Supreme Court, Article 3, Section 2, Clause 1: Hayburn's Case Document 312 Dall. 409, 1972.

73 U.S. Supreme Court, Article 3, Section 2, Clause 1: United States v. Yale Todd (1794), IN United States v. Ferreira Document 3713 How. 40, 1851.

${ }^{74}$ U.S. Supreme Court, Article 3, Section 2, Clause 1: Cooper v. Telfair Document 454 Dall. 14, 1800 .

75 U.S. Supreme Court, Article 3, Section 2, Clause 1: Cooper v. Telfair Document 454 Dall. 14; illiam Michael Treanor, «Judicial Review Before Marbury», Standford Law Review, 58.2 (2005), 455-562.

76 U.S. Supreme Court, Hylton v. United States: 3 U.S. Dall. 171, 1796.

77 Hay que resaltar que la Corte Suprema — pero sobre todo Samuel Chase — se declaró impedida para conocer tanto del primero ( No application has yet been made to the court, or to ourselves individually, and therefore, we have had some doubts as to the propriety of giving an opinion in a case which has not yet come regularly and judicially before us.», ver: U.S. Supreme Court. Article 3, Section 2, Clause 1: Hayburn's Case Document 312 Dall. 409, 1972) como del segundo caso («there is no adjudication of the Supreme Court itself upon the point...»; ver: U.S. Supreme Court. Article 3, Section 2, Clause 1: Cooper v. Telfair Document 454 Dall. 14, 1800). Ciertamente, la Corte agregó defectos de procedimiento. Pero esto no fue óbice para había consenso entre sus miembros sobre la importancia de aplicar las bases del control de constitucionalidad dejadas por Alexander Hamilton en el Federalista $\mathrm{n}^{\circ} 78$ ( «It is... a general opinion, it is expressly admitted by all this bar, and some of the Judges have, individually, in the Circuits, decided, that the Supreme Court can declare an act of Congress to be unconstitutional.»; ver: U.S. Supreme Court. Article 3, Section 2, Clause 1: Cooper v. Telfair...) y estas no serían aplicadas sino hasta 1803.

78 U.S. Supreme Court, Marbury v. Madison, 5 U.S. 137, 1803.

79 La famosa decisión Marbury vs. Madison de 1803 es recordada como la primera vez que una Constitución Política sirve de racero a los actos del poder. El encargado de proferirla fue Justice John Marshall, pasando a la historia como heredero de las ideas de Alexander Hamilton. Como ya se observó en este apartado del presente texto, Marshall retoma la opinión generalizada de sus pares y sienta los fundamentos de la Judicial Review. Primero en Marbury vs. Madison —resolviendo el caso de los «jueces de medianoche» y posteriormente McCulloch vs. Maryland; la primera establece las reglas del control de las leyes federales y la segunda establece las reglas para el control de las leyes de los Estados federados. Para Chief Justice Marshall el Artículo 3, Sección 2, cláusula 1, obligaba a los jueces a conservar la supremacía de la Constitución; era una posibilidad latente que los poderes enumerados y limitados del Congreso (Artículo I) no fueran un límite real para evitar que este desdibujara los límites establecidos 
argumento para la aparición efectiva de la Judicial Review resultó ser la ausencia de límites reales a los poderes públicos. No se podía caer en el absurdo de establecer límites sin clausurar la posibilidad de que estos pudieran transgredirlos a su guisa ${ }^{80}$. Pese al silencio del texto constitucional, Chief Justice Marshall se valió del citado Artículo III, Sección 1, interpretando de la frase «se deposita el poder judicial de los Estados Unidos...» como: «lo que los jueces han hecho tradicionalmente en el pasado». En otras palabras, pertenecía a los jueces la facultad desentrañar el sentido de las leyes tomando como referencia una norma superior.

Al igual que Hamilton, John Marshall ayuda a fomentar la idea del carácter absoluto de la Convención de 1787, manifestada en una norma escrita; la asamblea constituyente condiciona, en general, la acción de los poderes públicos. En ese orden de ideas, el juez debe ceñirse a lo que dice la norma de más alta jerarquía ${ }^{81}$. En suma, fue gracias a la Corte Suprema en otras decisiones ${ }^{82}$ que se desarrollaron las ideas del Federalista, la supremacía constitucional fue reconocida.

Teniendo en cuenta que esclarecimos el sentido de los límites constitucionales a los poderes públicos — aunado a los esfuerzos de la Corte Suprema de comienzos del siglo $\mathrm{XIX}^{83}$ - se hace necesario pasar ahora a un estudio del ejecutivo federal que permitan mostrar el sentido antitético del concepto de «presidencia imperial».

\section{LA PRESIDENCIA IMPERIAL COMO AMENAZA A LA ESTRUCTURA CONSTITUCIONAL}

Pese a que los redactores de la Constitución de 1787 estaban pensando en implantar un gobierno moderado ${ }^{84}$, el paso del tiempo permitió que algunos Presidentes aprovecharan dicha naturaleza para expandir el campo de sus competencias ${ }^{85}$. Dicha

a través de sus leyes. Ver: U.S. Supreme Court. Marbury v. Madison, 5 U.S. 137 (1803); Turner, K. (1960). «The Midnight Judges». Penn Law Review, 4(109), 1961, 494-523. http://scholarship.law. upenn.edu/cgi/viewcontent.cgi?article $=6949 \&$ context $=$ penn_law_review

${ }^{80}$ Ryan, E. (2007). «Federalism and the Tug of War Within: Seeking Checks and Balance in the Interjurisdictional». Maryland Law Review, 66(3), 503-667. https://doi.org/doi:10.2139/ssrn.1350008

81 U.S. Supreme Court, Marbury v. Madison, 5 U.S. 137.

${ }^{82}$ U.S. Supreme Court, Article 4, Section 2, Clause 1: Bayard v. Singleton 1 N.C, 1787; U.S. Supreme Court, Vanhorne's Lessee v. Dorrance 2 U.S. 304, 1795; Rodrigo González Quintero, «Ley Fundamental, Supremacía de La Constitución Y Control de Constitucionalidad: Una Aproximación Distinta a La Sentencia Marbury vs. Madison, Y a Los Orígenes de La Justicia Constitucional», Revista Jurídicas, 8.2 (2011), 13-29; U.S. Supreme Court, Hylton v. United States: 3 U.S. Dall. 171.

83 Winters, J. A. (1968). «General Principles of Constitutional Adjudication: The Political Foundations of Constitutional Law». William \& Mary Law Review, 10(2), 315-336.

84 Benjamin A Kleinerman, «The Constitutional Ambitions of James Madison's Presidency», Presidential Studies Quarterly, 44.1 (2014), 6-26 «https://doi.org/10.1111/psq.12085»

85 Elisabeth Zoller, Histoire du Gouvernement Présidentiel Aux États-Unis (Paris: Dalloz, 2011); Andrew Rudalevige, «The Contemporary Presidency: Executive Orders and Presidential Unilateralism», Presidential Studies Quarterly, 42.1 (2012), 138-60 «https://doi.org/10.1111/j.1741-5705.2012.03945.x». 
concentración de poderes ha ido resquebrajando el principio de la separación de poderes $^{86}$, propiciando asimismo el surgimiento de «la presidencia imperial» ${ }^{87}$. Esta exacerbación del régimen presidencial rompe con el equilibrio de los poderes públicos porque hace del gobierno moderado un gobierno unilateral, donde el ejecutivo no es controlado. Pero si la mecánica planteada por los Padres Fundadores era tan perfecta y elaborada, ¿cómo ha se explica que haya perdido tanto terreno frente a las ambiciones de uno solo de los tres poderes del gobierno federal? La respuesta no está, prima facie, en lo institucional, sino en lo personal ${ }^{88}$.

Es difícil dar una respuesta definitiva, pero sí pueden aportarse ciertos elementos para el debate, derivados del protagonismo del Presidente mismo. Por ende, el poder ejecutivo es causa y efecto de dicho desequilibrio: en 230 años de régimen presidencial en los Estados Unidos, la personalidad de todo aquel que haya sido elegido ha determinado su mandato ${ }^{89}$. Así, si su talante es desmesurado y ajeno a la prudencia, se pone en riesgo la institucionalidad o se corre el peligro de caer en la tiranía, cuya prevención es de la esencia de la Constitución de $1787^{90}$.

Se propone a continuación un estudio más detallado sobre la "presidencia imperial» en varios momentos: su (1.) aparición ${ }^{91}$, su (2.) puesta en marcha, su (3.) consolidación y su relación con las (4.) agencias administrativas federales (AAF) como ejemplo de consolidación de la «presidencia imperial». Todo esto estará seguido de un (5.) análisis sobre porvenir del concepto.

\section{Nacimiento de la «presidencia imperial»}

Jackson (1829-1837) y Lincoln (1861-1865) fueron los pioneros de la «presidencia imperial». El primero, Andrew Jackson, aprovechó su popularidad para ampliar el poder de la Presidencia; impuso al Congreso su veto en varias ocasiones ${ }^{92}$ que era

${ }^{86}$ Posner, E. A., \& Vermeule, A. (2011). The Executive Unbound: After the Madisonian Republic, New York, Oxford University Press.

${ }^{87}$ Fabbrini, S. (2009). El ascenso del príncipe democrático: quién gobierna y cómo se gobiernan las democracias, Buenos Aires: Fondo de Cultura Económica; Bacevich, A. J. (2008) The Limits of Power: The End of American Exceptionalism. New York: Metropolitan Books Henry Holt and Company.

${ }_{88}$ Twombly, J. (2013). The Progression of the American Presidency. Individuals, Empire, and Change (1st ed), New York: Palgrave Macmillan «doi: 10.1057/9781137300546»

${ }^{89}$ Franklin, D. P. (2014). Pitiful Giants. Presidents in Their Final Terms (1st ed), New York: Palgrave Macmillan «doi: 10.1057/9781137408242»

90 Posner, E. A., \& Vermeule, A. (2011). The Executive Unbound: After the Madisonian Republic, New York, Oxford University Press.

91 Ligado a los momentos de crisis donde son usados los poderes de guerra del Presidente, sus prerrogativas constitucionales fueron conceptualizadas por las decisiones a partir de McCulloch vs. Maryland. Ver: U.S. Supreme Court. Gibbons v. Ogden, 22 U.S. 9 Wheat. 11 (1824); ver igualmente: U.S. Supreme Court. Cohens v. Virginia, 19 U.S. (6 Wheat.) 264 (1821).

92 Franklin, D. P. (2014). Pitiful Giants. Presidents in Their Final Terms (1st ed.), New York, Palgrave Macmillan. https://doi.org/DOI 10.1057/9781137408242 
prerrogativa poco utilizada hasta entonces ${ }^{93}$. No puede afirmarse que su presidencia fue «imperial», pero fue uno de los primeros en autoproclamarse «representante directo del pueblo», asunto este que estaba por fuera del canon fijado por los Framers, puesto que la elección del jefe del ejecutivo federal era y es indirecta en virtud del Artículo II, Sección I, de la Constitución. A este respecto, es memorable el «Mensaje de Protesta» de Jackson dirigido al Senado el 15 de abril de $1834^{94}$. A pesar de que el Senado Federal prohibió su publicación en los medios ( The Senate ordered that it be not entered on the Journal»), es recordado por su virulencia y su invocación directa de la voluntad del pueblo, en un momento en que su estilo de gobierno es coartado por el control del Senado de la Unión.

Por su parte, Lincoln abolió la esclavitud acarreando, con ello, una guerra civil ${ }^{95}$. La primera situación se conjuró a través de la Proclamación número 9596. La segunda situación fue la llamada Guerra de Secesión (1861-1865). El Presidente Lincoln dirigió el ejército de la Unión a la victoria en la Batalla Gettysburg, pero no sin graves rasgos de autoritarismo que fueron justificados por la necesidad de mantener viva la Unión $^{97}$. Pese a ser el modelo para otros jefes del ejecutivo federal ${ }^{98}$, del gobierno de Lincoln no puede olvidarse la suspensión del privilegio de solicitud de Habeas Corpus con la Proclamación número $104^{99}$. Ni el Congreso, ni la Corte Suprema se opusieron.

Es de la esencia de la Constitución estadounidense el establecimiento de un modelo federal y presidencial. Las competencias de la confederación creada para la guerra se habían quedado cortas para responder las nuevas necesidades en época de paz. Se buscaron mecanismos para que los estados le transfirieran poderes a la unión y en la medida que esas competencias aumentaron, también aumentó el poder radicado en Washington. Cada vez que se fortalecía la federación, también se for-

${ }^{3}$ Gary L. Gregg. (1997). The Presidential Republic: Executive Representation and Deliberative Democracy, Boston, Rowman \& Littlefield Publishers.

94 Jackson, A. (2018). President Jackson's Message of Protest to the Senate; April 15, 1834. Retrieved February 10, 2018, from http://avalon.law.yale.edu/19th_century/ajack006.asp

95 Chambers, H. L. (2013). «Lincoln, The Emancipation Proclamation and Executive Power». Maryland Law Review, 73(100), 100-132

96 En otras Precidencias también trataron de reducir la segregación racial a través de sus prerrogativas, como la Orden Ejecutiva 8802 del 25 de 1941 de Franklin D. Roosevelt y la Orden Ejecutiva número 9981 de Truman, donde se prohíben: la discriminación racial en la industria militar nacional y la discriminación al interior de las fuerzas armadas, respectivamente; ver: President of the United States of America, Proclamation 95 - (U.S., 1863) «http://www.presidency.ucsb.edu/ ws/?pid=69880»; James E Underwood, «Lincoln: A Weberian Politician Meets the Constitution», Presidential Studies Quarterly, 34.2 (2004), 341-65 https://doi.org/10.1111/j.1741-5705.2004.00048.x

97 Zoller, E. (2011) Histoire du gouvernement présidentiel aux États-Unis. Paris: Dalloz, pp. 122149.

98 Ortiz JR, D. (2004). «La Presidencia de los Estados Unidos ¿un modelo de poder ejecutivo?». Espacio Tiempo Y Forma. Serie V, Historia Contemporánea, (16), 13-66 «https://doi.org/10.5944/ etfv.16.2004.3084»

99 President of the United States of America, Proclamation 104 - Suspending the Writ of Habeas Corpus Throughout the United States, 1863. 
talecía al Congreso, la Corte Suprema y al Presidente. ${ }^{100}$ Pero este último iba ganando protagonismo, mientras que los dos primeros poderes en términos de Vermeule, se abnegaban, es decir se relegaban voluntariamente en favor de la administración. La interpretación dada con el paso del tiempo a la Constitución de los EUA permitió concebirla no solo como un pacto de unión entre los estados, sino también como el instrumento de cesión competencial de estos en favor de la federación y de esta en favor de la administración. Es lo que el citado jurista de Harvard ha llamado el paso del imperio del derecho (law's empire) al estado administrativo (administrative state). ${ }^{101}$

\section{Consolidación de la «presidencia imperial»}

La transición de los siglos XIX y Xx trajo varios huéspedes a la Casa Blanca cuyo carácter dominante les ayudaría a hacer de EUA un imperio. En primer lugar, bajo la presidencia de William Mckinley (1897-1901) ${ }^{102}$ los EUA desplazarían a las antiguas potencias colonialistas en el continente americano y el Océano Pacífico ${ }^{103}$. En 1898, entraron en guerra con España, arrebatándole el dominio sobre Cuba y Puerto Rico ${ }^{104}$, así como también sobre las Islas Filipinas ${ }^{105}$. Dichas victorias militares fueron posibles, en gran medida, a los poderes constitucionales de guerra (Artículo II, Sección II, Cláusula 1) con los que está revestido el Presidente ${ }^{106}$.

En segundo lugar, Theodore Roosevelt (1901-1909) se sirvió de su popularidad para aumentar los poderes del ejecutivo; él fue quien mejor parece haberse servido de los medios para gobernar ${ }^{107}$, siendo de algún modo el precursor de una práctica, hoy, recurrente ${ }^{108}$. Esto se debió a que su influencia sobre el Congreso era limita-

100 «The powers not delegated to the United States by the Constitution, nor prohibited by it to the States, are reserved to the States respectively, or to the people.» Amendment 10 - Powers of the States and People. Ratified 12/15/1791.

101 Vermeule, A. (2016) Law's Abnegation. From Law's Empire to the Administrative State (1st ed.), Cambridge: Harvard University Press.

102 Genovese, M. A. (2001). The Power of the American Presidency: 1789-2000, New York, Oxford University Press.

${ }_{103}$ Healy, D. J. (1970) US Expansionism: The Imperialist Urge in the 1890s, Madison: Univesity of Wisconsin Press.

104 Healy, D. J. (1970). US Expansionism: The Imperialist Urge in the 1890s, Madison, Univesity of Wisconsin Press.

105 Healy, D. J. (1970). US Expansionism: The Imperialist Urge in the 1890s, Madison, Univesity of Wisconsin Press.

106 U.S. Supreme Court, Cohens v. Virginia, 19 U.S. (6 Wheat.) 264, 1821; U.S. Supreme Court, McCulloch v. Maryland, 17 U.S. 4 Wheat. 316 316, 1819.

107 Zoller, E. (2011) Histoire du gouvernement présidentiel aux États-Unis. Paris: Dalloz, pp.210-212.

108 Major, M. (2014). The Unilateral Presidency and the News Media. The Politics of Framing Executive Power, New York: Palgrave Macmillan, pp.121-122 doi: «10.1057/9781137387899» 
$\mathrm{da}^{109}$ y para sobreponerse a esta dificultad, sus acciones sirvieron para desarrollar la «presidencia imperial». Veamos dos de ellas.

La primera es la invasión a la República Dominicana (1904-1905). Esta mostró el verdadero alcance de los poderes de la Presidencia. Cabe recordar que al firmarse el tratado internacional postbellum con Santo Domingo, este no fue ratificado por el Senado. Frente este hecho, la doctrina de Teddy Roosevelt llamada bully pulpit, hizo fútil la oposición: la contumacia del Congreso era aprovechada por la acción unilateral del ejecutivo ${ }^{110}$, haciendo ver todo control como un obstáculo al progreso ${ }^{111}$. Finalmente, Roosevelt adoptaría él mismo el acuerdo con Santo Domingo; su vigencia sería constatada en 1917, cuando la marina estadounidense coordinaría la ocupación militar de Santo Domingo ${ }^{112}$.

La segunda acción de Roosevelt que constituye un desarrollo de la «presidencia imperial» tuvo lugar en 1903. Con fundamento en la Orden Ejecutiva número 283, del 8 de diciembre de $1904^{113}$, los estadounidenses comenzaron a ver la manera de ocupar el istmo de Panamá para facilitar el tránsito interoceánico de sus navíos mercantes. Este acto de autoritarismo transfronterizo, constituye otra prueba de los nuevos poderes del Presidente.

En suma, luego de vistos los dos casos anteriores, puede afirmarse que ambas acciones tienen un fundamento normativo: si bien Constitución no concede expresamente esa competencia al Presidente, tampoco se la prohíbe ${ }^{114}$.

El camino hacia la consolidación de la «presidencia imperial», tiene también la participación, en tercer lugar, el treintaidosavo presidente de los Estados Unidos, Franklin Delano Roosevelt (1933-1945). Expidió un promedio anual de 310 órdenes ejecutivas, pero estas se justifican, históricamente, por las terribles catástrofes con las que tuvo que lidiar: la gran depresión de 1929 y la Segunda Guerra Mundial (19391945). Desde el punto de vista del constitucionalismo, la manera en que lograron conjurarse ambas calamidades tiene que ver con la subordinación del poder legislativo y del poder judicial, es decir, a las nociones que tomamos por consolidadas (supra 1).

109 Healy, D. J. (1970). US Expansionism: The Imperialist Urge in the 1890s, Madison, Univesity of Wisconsin Press.

110 Zoller, Histoire Du Gouvernement Présidentiel Aux États-Unis, pp. 225-27.

111 Mueller, J. E. (2016). «Success and Failure in Using the Bully Pulpit: Lincoln, Roosevelt, and Taft and the Importance of Press Relations». Presidential Studies Quarterly, 46(4), 943-946. https://doi. org/10.1111/psq.12327

112 «Proclamation of the Military Occupation of Santo Domingo by the United States. (1917)». The American Journal of International Law, 11(2 Supplement: Official Documents (Apr., 1917)), 94-96. https://doi.org/DOI: 10.2307/2212199

113 President of the United States of America, Executive Order 283-Waiving Civil Service Requirements of United States Citizenship for Positions on Isthmus of Panama, December 8, 1904. Online by Wikisource. https://en.wikisource.org/wiki/Executive_Order_283

114 Mueller, J. E. (2016). «Success and Failure in Using the Bully Pulpit: Lincoln, Roosevelt, and Taft and the Importance of Press Relations». Presidential Studies Quarterly, 46(4), 943-946 «https://doi. org/10.1111/psq.12327» 
Con respecto al legislativo, Franklin D. Roosevelt no solo contaba con mayorías que lo apoyaran en el Congreso, sino también con los extraordinarios poderes que el carácter voluntarioso de Jackson y Teddy Roosevelt habían institucionalizado $^{115}$. Su liderazgo fue acatado por las mayorías del Partido Republicano a pesar de que su ideología dictara que el gobierno federal debía ejercerse de forma limi$\operatorname{tada}^{116}$.

En consecuencia, no ha de sernos extraña que la creación mediante orden ejecutiva de «campos para la concentración» de japoneses durante la guerra no haya sido soslayada por el Congreso ${ }^{117}$. Teniendo en cuenta que el Imperio Japonés era el enemigo y no los descendientes de japoneses — que a la sazón eran ciudadanos estadounidenses — la Orden Ejecutiva $9066^{118}$ fue atacada ante la Corte Suprema, pero el alto tribunal declaró su constitucionalidad en la decisión Korematsu vs. United States ${ }^{119}$. Los controles interpuestos contra las órdenes de Franklin D. Roosevelt se presentarían un par de veces más en las decisiones Youngstown Sheet \& Tube Co. vs. Sawyer ${ }^{120}$ y en Environmental Protection Agency (EPA) vs. Mink ${ }^{121}$.

En complemento, con respecto al poder judicial, el Presidente Franklin D. Roosevelt también tuvo que enfrentarse con la Corte Suprema para hacer pasar el New $D e a l^{122}$. La lucha entre el ejecutivo y el precitado tribunal giró en torno a desmantelar el precedente sobre el Sustantive Due Process of Law $w^{123}$. Primero, la Corte Suprema, en la decisión Home Building \& Loan Assn. vs. Blaisdell ${ }^{124}$, revisa levemente una medida de urgencia económica tomada por el Presidente, aunque recordándole que sus poderes deben ceñirse a las directrices de su política. Segundo, los controles a las medidas derivadas del New Deal comienzan a hacerse más recios, cuando, por ejemplo, la decisión Panama Refining Co. vs Ryan ${ }^{125}$ censura la iniciativa presidencial anulando una ley federal (Connally Hot Oil Act of 1935) por ser fruto de una usurpación de competencias legislativas, ya que equiparaba las deudas privadas a las deudas estatales. Igual ocurriría en la decisión United States vs. Bulter ${ }^{126}$, donde la Corte invalida

115 Zoller, E. (2011) Histoire du gouvernement présidentiel aux États-Unis. Paris: Dalloz, pp. 252-280.

116 Roosevelt, F. D. (1938) «The year of crisis, 1933: with a special introduction and explanatory notes by President Roosevelt», in Rosenman, S. I. (ed.), The public papers and addresses of Franklin D. Roosevelt (Book 1), New York: Random House, p. 622.

117 Fisher, L. (2005) «Judicial Review of the War Power», Presidential Studies Quarterly, 35(3), pp. 466-495 (v. particularmente, p.438) «doi: 10.1111/j.1741-5705.2005.00260.x»

118 President of the United States of America, Executive Order 9066-Authorizing the Secretary of War To Prescribe Military Areas, February 19, 1942, Gerhard Peters and John T. Woolley, The American Presidency Project http://www.presidency.ucsb.edu/ws/?pid=61698

119 U.S. Supreme Court, Korematsu v. United States, 323 U.S. 214, 1944.

120 U.S. Supreme Court, Youngstown Sheet \& Tube Co. v. Sawyer, 343 U.S. 579, 1952.

121 U.S. Supreme Court, EPA v. Mink, 410 U.S. 73, 1973.

122 Zoller, E. (2011) Histoire du gouvernement présidentiel aux États-Unis. Paris: Dalloz, pp. 265-277.

123 Este término contenía la llamada Due process and equal protection clauses of the Fourteenth Amendment.

124 U.S. Supreme Court, Home Building \& Loan Assn. v. Blaisdell, 290 U.S. 398, 1934.

125 U.S. Supreme Court, «Panama Refining Co. v. Ryan, 293 U.S. 388», 1935.

126 U.S. Supreme Court, United States v. Butler, 297 U.S. 1, 1936. 
la ley (Agricultural Adjustment Act of 1933) que estabilizaría los precios de productos agrícolas; pese a dicha medida se tomaba para garantizar la prosperidad y levantar un país en crisis, la Corte Suprema prefería la protección de las libertades individuales por sobre el bien común.

Cansado de una situación que ponía en peligro el New Deal, Franklin D. Roosevelt usa su control sobre el Congreso y saca provecho de los medios de comunicación para referirse a la Corte Suprema como: «nueve viejos que se oponían al progreso del país». Entonces, en 1937 — posterior a la reelección de Roosevelt con el respaldo del Congreso y del pueblo soberano — se propone una reforma judicial, aunque sin dejar claro que se trataba de aumentar el número de miembros de la Corte Suprema ${ }^{127}$. Sancionar una ley semejante le aseguraba la posibilidad de nombrar seis nuevos miembros, es decir, el poder de manejar las mayoritarias del supremo tribunal a través de miembros que serían nombrados por sus mayorías. En consecuencia, ese mismo año y antes de que se promulgara el proyecto de ley, la Corte misma se apresuró a fallar el caso West Coast Hotel Co. vs. Parrish ${ }^{128}$. En la sentencia se desmonta el precedente de la decisión Adkins vs. Children's Hospital ${ }^{129}$, dejando claro que sus miembros no podrían seguir dándole carácter absoluto a la ninguna libertad.

\section{Plenitud de la «presidencia imperial»}

Una vez esbozada la evolución de la «presidencia imperial», pueden abordarse ahora algunos casos para mostrar que fueron muchos los Presidentes que usaron las órdenes ejecutivas para enviar tropas al extranjero. No hubo autorización previa del Congreso de los Estados Unidos.

Tabla 1. Presidentes que enviaron tropas al extranjero

\begin{tabular}{|l|l|}
\hline \multicolumn{1}{|c|}{ PRESIDENTE } & \multicolumn{1}{c|}{ CONFLICTO } \\
\hline Jarry Truman & Guerra de Corea (1950-1953) \\
\hline Lyndon B. Johnson & Guerra de Vietnam (1955-1975) \\
\hline Richard Nixon & Invasión a Camboya (1970) \\
\hline Ronald Reagan & Invasión a Granada (1983) \\
\hline George H. W. Bush & $\begin{array}{l}\text { Invasión a Panamá (1989-1990) } \\
\text { Guerra del Golfo (1990-1991) }\end{array}$ \\
\hline Bill Clinton & Misión militar en Somalia (Mogadishu, 1993) y Envío de tropas a Haití (1994) \\
\hline George W. Bush & Invasión a Iraq (2001) y Afganistán (2001) \\
\hline
\end{tabular}

Fuente: elaboración propia.

${ }^{127}$ Jackson, R. H. (1962). The struggle for judicial supremacy: A study of a crisis in American power politics, New York, Vintage books.

128 U.S. Supreme Court, West Coast Hotel Co. v. Parrish, 300 U.S. 379, 1937.

129 U.S. Supreme Court, Adkins v. Children's Hosp, 1923. 
No puede olvidarse que luego del 11 de septiembre de 2001, el Presidente Bush expidió dos órdenes: Orden Ejecutiva número 12774 del 27 de septiembre de $1991^{130}$, cuya sección 3. a estructura una serie de organismos para la lucha contra el terrorismo; y la otra, es la Orden Ejecutiva número $13234^{131}$. A partir de estas se crearon tribunales militares competentes para juzgar civiles extranjeros sospechosos de terrorismo. Agitando el patriotismo ${ }^{132}$, el Bush Jr. logró acrecentar el poder de las agencias de seguridad a un nivel que no se veía desde el Gobierno de Franklin D. Roosevelt.

\section{Las agencias administrativas federales como instrumento de consolidación de la "presidencia imperial»}

La consolidación de la «presidencia imperial» no es una consecuencia exclusiva de las órdenes ejecutivas; estas van acompasadas del efecto de aquéllas sobre las $\mathrm{AAF}^{133}$, en algo que se denomina como "políticas internas de la rama ejecutiva» ${ }^{134}$; e.g. con la orden ejecutiva 12866 de $1993^{135}$, Clinton desarrolla su Regulatory Planning and Review, creando el Office of Information and Regulatory Affairs (OIRA), dependiente del Office of Management and Budget (OMB); la Sección $2^{136}$ de la orden estableció

130 President of the United States of America, Executive Order 12774-Continuance of Certain Federal Advisory Committees, Septembre 27, 1991. https://en.wikisource.org/wiki/Executive_Order_12774

131 President of the United States of America, Executive Order 13234_Presidential Task Force on Citizen Preparedness in the War on Terrorism (consultado, en: http://www.presidency.ucsb.edu/ $\mathrm{ws} /$ ?pid=61515, el 22 de abril 2018).

132 Martínez Mulero, I. (2011) «El frenesí legislativo después del 11-S, ¿Derechos humanos versus seguridad nacional?», Revista Aequitas, 1, pp. 71-82.

133 Encontramos una definición de agencia (agencie) en el APA: «Title 5, Part I, Chapter 5, Subchapter II, § 551. For the purpose of this subchapter-/ (1) «agency» means each authority of the Government of the United States, whether or not it is within or subject to review by another agency, but does not include- / (A) the Congress; / (B) the courts of the United States; / (C) the governments of the territories or possessions of the United States; / (D) the government of the District of Columbia; / or except as to the requirements of section 552 of this title- / (E) agencies composed of representatives of the parties or of representatives of organizations of the parties to the disputes determined by them; / (F) courts martial and military commissions; / (G) military authority exercised in the field in time of war or in occupied territory; or / (H) functions conferred by sections 1738, 1739, 1743, and 1744 of title 12; subchapter II of chapter 471 of title 49; or sections 1884, 1891-1902, and former section 1641(b)(2), of title 50, appendix;» (consultado en: https://www.law.cornell.edu/uscode/ text/5/551\#fn002006-ref).

134 Daniel J. Hemel and Aaron L. Nielson, «Chevron Step One-and-a-Half», The University of Chicago Law Review, 84.2 (2017), 757-824 (pp. 795-97).

135 President of the United States of America, Executive Order 12866, 1993 «http://www.presidency. ucsb.edu/ws/?pid=61560».

136 «Sec.2. Organization. An efficient regulatory planning and review process is vital to ensure that the Federal Government's regulatory system best serves the American people. [...] / (b) The Office of Management and Budget. Coordinated review of agency rulemaking is necessary to ensure that regulations are consistent with applicable law, the President's priorities, and the principles set forth in this Executive order, and that decisions made by one agency do not conflict with the policies or actions 
un férreo sistema de obediencia y control, subordinando y unificando los criterios de acción de las agencias.

Por antonomasia, estas materializan el Administrative State, burocracia ${ }^{137}$ que crece de manera proporcional a las capacidades y ambiciones del Presidente de turno ${ }^{138}$. Consideradas como the fourth branch of government están consagradas por el APA de 1946 mas no en la Constitución, pese a su relevancia para el orden constitucional ${ }^{139}$.

De esta semejanza esencial con las órdenes ejecutivas surge la cuestión fundamental de este apartado: ¿cómo controlar un organismo que extiende los poderes implícitos del ejecutivo? Y para responderla ${ }^{140}$, hay que comprender previamente las (i.) características básicas de estas agencias, (ii.) su evolución y (iii.) las críticas que sucintan en la doctrina estadounidense.

(i.) En primer lugar: naturaleza y clasificación. De un lado, la agencias surgen de la necesidad de diseñar e implementar normas que regulen actividades productivas —e.g. economía, ciencia y seguridad ${ }^{141}$ - y que requieren experticia técnica que rebasa la administración convencional ${ }^{142}$. Del otro lado, es posible clasificarlas en dos especies: administrativas regulares (AAR), dependientes del Presidente; y las administrativas independientes (AAI), dotadas de una autonomía de la institución presidencial que fueron perdiendo con el paso del tiempo en favor de esta.

(ii.) En segundo lugar: su historia está marcada por roces con los otros dos departamentos del gobierno federal ${ }^{143}$, pero — sobre todo- por la lucha por mantener su independencia; el caso de las AAI resulta paradigmático y se hace necesario estudiar-

taken or planned by another agency. The Office of Management and Budget (OMB) shall carry out that review function. Within OMB, the Office of Information and Regulatory Affairs (OIRA) is the repository of expertise concerning regulatory issues, including methodologies and procedures that affect more than one agency, this Executive order, and the President's regulatory policies. To the extent permitted by law, OMB shall provide guidance to agencies and assist the President, the Vice President, and other regulatory policy advisors to the President in regulatory planning and shall be the entity that reviews individual regulations, as provided by this Executive order.»

137 Entendida como la manera del ejecutivo de llegar a los ciudadanos y garantizar que su programa de gobierno se realice.

${ }^{138}$ Lowi, Theodore J., Benjamin Ginsberg, and Stephen Ansolabehere, American Gouvernment. Power and Purpose, 14th edn (New York: W.W. Norton \& Company, Inc, 2017), pp. 290-299.

139 Vermeule, Adrian, The Constitution of Risk (New York: Cambridge University Press, 2013), p. 163.

${ }^{140}$ Comprendiendo el rol de las AAF en el creciente influjo de la Presidencia sobre las demás ramas.

141 Lowi, Theodore J., Benjamin Ginsberg, and Stephen Ansolabehere, American Gouvernment. Power and Purpose, 14th edn (New York: W.W. Norton \& Company, Inc, 2017); Vermeule, A. (2016). Law's Abnegation. From Law's Empire to the Administrative State (1st ed.), Cambridge, Harvard University Press, pp. 130-134.

${ }_{142}$ Vermeule, Adrian, The Constitution of Risk (New York: Cambridge University Press, 2013), pp. 165-178.

143 Sheehan, Reginald S., «Federal Agencies and the Supreme Court. An Analysis of Litigation Outcomes, 1953-1988», American Politics Quarterly, 20 (1992), 478-500 «https://doi.org/https://doi. org/10.1177/1532673X9202000407» 
lo. La Corte Suprema se pronunció en dos fallos históricos. De un lado, en Myers vs U.S. ${ }^{144}$, declaró la inconstitucionalidad de una norma que le prohibía al Presidente remover los executive officers de su cargo, con fundamento en la supremacía presidencial sobre el poder ejecutivo y la administración. Por otro lado, en Humphrey's Executor vs U.S. ${ }^{145}$ de 1935 matizó el precedente; a través de leyes, el Congreso podría limitar la discrecionalidad de la Presidencia para remover a directivos de las AAF.

Ciertamente, si —en términos del Administrative State - la tendencia era reducir la influencia presidencial sobre las AAI, esta fue cambiando al terminar el siglo xx. En Morrison vs. Olson ${ }^{146}$ y Bilzerian vs. $S E C^{147}$, la Corte reafirmó la prevalencia del Presidente sobre las de las AAI para diseñar, implementar y regular políticas públicas. Esto último encaja en el llamado del Presidente a las AAI a someterse a sus iniciativas a través de órdenes ejecutivas. Son ejemplos: Primero, dos órdenes ejecutivas durante el gobierno Reagan. Primero, la 12291 de $1981^{148}$, donde pidió a las AAI no expedir normas de regulación sectorial hasta que el proyecto de regulación tuviese el visto bueno del gobierno ${ }^{149}$ y la orden 12498 de $1985^{150}$, donde se impone a las AAI presentar una proyección anualizada de su actividad reguladora que debería ser aprobada por el OMB, agencia que depende directamente del gobierno. Segundo, la precitada orden 12866 de 1993: Clinton ordena a las AAI presentar un informe al OIRA, para así alinear el Administrative State a las políticas presidenciales. Agreguemos, finalmente, que hoy en día el ejecutivo propone y defiende ante el Congreso el presupuesto de la mayoría de las $\mathrm{AAI}^{151}$; por el contrario, solamente unas pocas pueden hacerlo directamente $^{152}$, aunque supeditados a que la Casa Blanca pueda cuestionar su presupuestos ante el Congreso.

(iii.) En tercer lugar: la crítica a la relación entre «presidencia imperial» y las AAF nos lleva reflexionar sobre dos tópicos: la usurpación de competencias y el control sobre estas agencias ${ }^{153}$ (que es en últimas, la pregunta de partida de este apartado 4). De un lado, como reguladores, las AAF desplazan al Legislatif deparment; y, a su vez,

${ }_{144}$ U.S. Supreme Court. Myers v. United States, 272 U.S. 52 (1925)

145 US. Supreme Court, 295 U.S. 602. Humphrey’s Executor v. United States (No. 637).

146 US. Supreme Court, Morrison v. Olson, 487 U.S. 654 (1988).

147 US. Supreme Court, Bilzerian v. SEC, 146 B.R. 871 (Bankr. M.D.Fla.1992).

148 President of the United States of America, Executive Order 12291, 1981.

149 Ver «Section 2» de la orden ejecutiva 12291.

${ }_{150}$ President of the United States of America, Executive Order 12498, 1985

151 Por regla general las AAI tienen el deber de presentar sus proyectos presupuestales ante la Office of Management and Budget (OMB), que es la agencia federal encargada de adecuar dichos presupuestos a las políticas del Presidente de los Estados Unidos.

${ }^{152}$ Las siguientes agencias pueden presentar directamente su proyecto de presupuesto ante el Congreso de los Estados Unidos: la Federal Communications Commission (FCC), el Board of Governors of the Federal Reserve System (BGFRS), la Federal Energy Regulatory Commission (FERC) y la Commodities Trading Futures Commission (CFTC).

${ }_{153}$ Lowi, T. J., Ginsberg, B. and Ansolabehere, S. (2017) American Gouvernment. Power and Purpose (14th ed.), New York: W.W. Norton \& Company, Inc., 609 pp. 
como organismos de vigilancia y control, las AAF desplazan al Judial department por sus competencias sancionatorias y de resolución de conflictos.

La dificultad de este «desplazamiento» es, paradójicamente, la independencia. Por ejemplo, si una AAF regula una actividad particular, el alcance y modo de su regulación se sustrae al control que normalmente tiene la actividad legislativa, lo que las hace independientes; sin embargo, se cree que el Presidente puede minar el gobierno representativo y la alternancia en el poder $^{154}$ imponiendo su visión a las AAF sirviéndose de sus órdenes ejecutivas. Pero, pese a lo anterior, las agencias pueden resistir la implementación de estas.

La paradoja se expande, pues el ckecks and balances ya no se hace solamente por parte del legislativo y el judicial, sino también por la llamada fourth branch of government, como ha ocurrido con la EPA, por ejemplo ${ }^{155}$. Es decir, una visión crítica - y no solamente institucional- muestra que «sin idolatría», la separación de poderes puede ser reinterpretada en favor de una visión muy moderna que fragiliza el derecho como expresión de la voluntad del poder legislativo ${ }^{156}$.

Su poder simbólico y su eficacia se ven diezmadas por las órdenes ejecutivas y la burocracia - y en ella las AAF — como expresión del Administrative State ${ }^{157}$. Hoy por hoy, para la Presidencia, resignarse a cumplir la ley es un asunto de autocontrol y no de una imposición del sistema frenos y contrapesos ${ }^{158}$. Puede afirmarse, así, que el imperio de la ley cede al «presidencialismo imperial». Dicha cesión, empero, puede no ser verdaderamente la «abnegación» de la que habla Vermeule. Primero, porque es difícil de controlar y, segundo, porque el Administrative State crea en su seno una suerte de resistencia y una micro-mecánica de control que pese a todo está sometida al control porque el poder legislativo ha definido la interpretación de las agencias —y con ello su fuerza- a una indeterminación de las materias que controla, en última instancia, el juez ${ }^{159}$.

${ }^{154}$ Vermeule, A. (2013) The Constitution of Risk. New York: Cambridge University Press, pp. 182185.

155 Henneberger, M. (2016) «How the government could resist President Trump's orders», The Washington Post. (cons. en: https://www.washingtonpost.com/posteverything/wp/2016/09/09/how-thegovernment-could-resist-president-trumps-orders/?noredirect $=$ on\&utm_term $=.9 \mathrm{da} 38 \mathrm{~b} 54 \mathrm{a} 7 \mathrm{f3}$ ).

156 Vermeule, A. (2016) Law's Abnegation. From Law's Empire to the Administrative State (1st ed.), Cambridge: Harvard University Press, pp. 66-86.

157 Vermeule, A. (2016) Law's Abnegation. From Law's Empire to the Administrative State (1st ed.), Cambridge: Harvard University Press.

158 Vermeule, A. (2016) Law's Abnegation. From Law's Empire to the Administrative State (1st ed.), Cambridge: Harvard University Press, pp. 209-219.

159 Posner, E. A. and Vermeule, A. (2011) The Executive Unbound: After the Madisonian Republic, New York: Oxford University Press, pp. 127-130.

El mismo texto de la ley que regula los poderes federales establece que: «Title 5, Part I, Chapter 7, $\S 706$. To the extent necessary to decision and when presented, the reviewing court shall decide all relevant questions of law, interpret constitutional and statutory provisions, and determine the meaning or applicability of the terms of an agency action. The reviewing court shall-/ (1) compel agency action unlawfully withheld or unreasonably delayed; and / (2) hold unlawful and set aside agency action, find- 
En última instancia, el concepto de «deferencia administrativa» ${ }^{160}$ se impone porque se quiere un margen amplio de discrecionalidad para el desarrollo de las actividades administrativas. Concretamente, las AAF gozan de una peculiar autorización o deferencia, consecuencia del caso Chevron vs N.R.D.C. ${ }^{161}$. Esta jurisprudencia evolucionó en lo que se conoce como Chevron pasos uno ${ }^{162}$, uno y medio ${ }^{163} \mathrm{y} \mathrm{dos}^{164}, \mathrm{y} \mathrm{da}$ amplias facultades a la interpretación administrativa de la ley ${ }^{165}$. Esta extensión de su interpretación de los puntos oscuros que la ley no define, fue respetada porque, en principio, las AAF no son simples paneles de expertos, sino órganos que imponen una visión política, y de acción política, tal y como expresa Clinton en su orden ejecutiva $12866^{166}$ : se trata de acercar el gobierno federal a los ciudadanos ${ }^{167}$.

Las evoluciones más recientes regla de deferencia emanada de Chevron y decisiones como Auer v. Robbins ${ }^{168}$ parecen mostrar que el control o review de los actos de las AAF está acercándose. Sin embargo, esta predicción puede ser apresurada ${ }^{169}$. Si bien desde 2016 se ha intentado reducirle poder a la doctrina del deference por parte del juez

ings, and conclusions found to be- / (A) arbitrary, capricious, an abuse of discretion, or otherwise not in accordance with law; / (B) contrary to constitutional right, power, privilege, or immunity; / (C) in excess of statutory jurisdiction, authority, or limitations, or short of statutory right; / (D) without observance of procedure required by law; / (E) unsupported by substantial evidence in a case subject to sections 556 and 557 of this title or otherwise reviewed on the record of an agency hearing provided by statute; or / (F) unwarranted by the facts to the extent that the facts are subject to trial de novo by the reviewing court. / In making the foregoing determinations, the court shall review the whole record or those parts of it cited by a party, and due account shall be taken of the rule of prejudicial error.»

${ }_{160} \mathrm{Al}$ respect, Justice Antonin Scalia dijo: «Five Terms ago, the Supreme Court issued its opinion in the case of Chevron, U.S.A., Inc. v. NRDC, I which announced the principle that the courts will accept an agency's reasonable interpretation of the ambiguous terms of a statute that the agency administers.»

${ }^{161}$ US. Supreme Court, Chevron U.S. A. Inc. v. Natural Resources Defense Council, Inc., 467 U. S. 837 (1984); también sobre esta regla de precedente que ampara la doctrina o regla del Chevron deference, ver: US. Supreme Court, Auer v. Robbins, 519 U.S. 452 (1997); US. Supreme Court, INS v. AguirreAguirre, 526 U. S. 415 (1999); US. Supreme Court, Negusie v. Holder, 555 U.S. 511 (2009).

${ }_{162}$ Harvard Law Review, «How Clear Is Clear» in Chevron's Step One?», Harvard Law Review, 118.5 (2005), 1687-1708.

${ }^{163}$ Hemel, D. J. and Nielson, A. L. (2017) «Chevron Step One-and-a-Half», The University of Chicago Law Review, 84(2), pp. 757-824..

${ }^{164}$ Levin, R. M. (1997) «The Anatomy of Chevron: Step Two Reconsidered», Chicago-Kent Law Review, 72(4), pp. 1253-1297.

165 Scalia, A. (1989) «Judicial Deference to Administrative Interpretations of Law», Duke Law Journal, 511(3), pp. 511-521.

166 President of the United States of America, Executive Order 12866, 1993.

167 Datla, K. and Revesz, R. L. (2013) «Deconstructing Independent Agencies (and Executive Agencies)», Cornell Law Review, 98(4), pp. 769-843.

168 Otorga la mayor autonomía a las agencias para interpretar y, por lo tanto, para fijar el alcance de sus propios reglamentos, Auer deference; ver: US. Supreme Court, Auer v. Robbins, 519 U.S. 452 (1997).

169 Los comentadores de las decisiones de la doctrina del Chevron son conscientes desde hace más de una década; ver: Manning, J. F. (1996) «Constitutional Structure and Judicial Deference to Agency Interpretations of Agency Rules», Columbia Law Review, 96(3), pp. 612-696, «doi: 10.2307/1123259» 
Thomas y Neil Gorsuch de la Corte Suprema ${ }^{170}$, aún el destino de esta prerrogativa del ejecutivo para escapar al control que se impone a sus agencias es la permanencia. La Corte Suprema se ha negado, por ejemplo, recientemente a reconsiderar su precedente en la decisión Garco Construction, Inc. v. Speer ${ }^{171}$, donde Thomas tiene una opinión disidente que se sustenta en la advertencia de los Framers sobre la acumulación poderes $^{172}$. Finalmente, es reciente la noticia de que el Estado de Arizona promulgó la House Bill número $2238^{173}$ que revierte contrarresta los efectos del deference sobre Arizona, el control es del poder judicial según los literales E, F y G. Entonces, nos encontramos frente a estrategias para menguar las fuerzas del «presidencia imperial» y someter, indirectamente, sus decisiones al imperio del derecho, y en últimas del constitucionalismo tradicional ${ }^{174}$.

170 Adler, J. H. (2016) «Supreme Court declines to reconsider deference to agency interpretations of agency regulations», The Washington Post, 16 May (consultado en: https://www.washingtonpost.com/ news/volokh-conspiracy/wp/2016/05/16/supreme-court-declines-to-reconsider-deference-to-agencyinterpretations-of-agency-regulations/? noredirect $=$ on\&utm_term $=. d 44 a 0412$ eaea).

171 U.S. Supreme Court, Garco Construction, Inc. v. Robert M. Speer, Acting secretary of the Army, 583 (2018).

172 «Because this Court has passed up another opportunity to remedy «precisely the accumulation of governmental powers that the Framers warned against,» id., at ___ (slip op., at 16), I respectfully dissent from the denial of certiorari.» U.S. Supreme Court, Garco Construction, Inc. v. Robert M. Speer, Acting secretary of the Army, 583 u.s. (2018), Thomas, J., dissenting.

173 La norma denominada Law H.B. 2238 revierte la jurisprudencia de la Corte sobre el control que las agencias ejercen sobre sus propios actos. Ahora el control es del poder judicial, como consta a partir de los literales $\mathrm{C}$ y D, pero especialmente en los E, F y G que a continuación se transcribe: «E. After reviewing the administrative record and supplementing evidence presented at the evidentiary hearing, the court may affirm, reverse, modify or vacate and remand the agency action. The court shall affirm the agency action unless the court concludes that the agency's action is contrary to law, is not supported by substantial evidence, is arbitrary and capricious or is an abuse of discretion. IN A PROCEEDING BROUGHT BY OR AGAINST THE REGULATED PARTY, THE COURT SHALL DECIDE ALL QUESTIONS OF LAW, INCLUDING THE INTERPRETATION OF A CONSTITUTIONAL OR STATUTORY PROVISION OR A RULE ADOPTED BY AN AGENCY, WITHOUT DEFERENCE TO ANY PREVIOUS DETERMINATION THAT MAY HAVE BEEN MADE ON THE QUESTION BY THE AGENCY. NOTWITHSTANDING ANY OTHER LAW, THIS SUBSECTION APPLIES IN ANY ACTION FOR JUDICIAL REVIEW OF ANY AGENCY ACTION THAT IS AUTHORIZED BY LAW. / F. NOTWITHSTANDING SUBSECTION E OF THIS SECTION, IF THE ACTION ARISES OUT OF TITLE 20, CHAPTER 15, ARTICLE 2, THE COURT SHALL AFFIRM THE AGENCY ACTION UNLESS AFTER REVIEWING THE ADMINISTRATIVE RECORD AND SUPPLEMENTING EVIDENCE PRESENTED AT THE EVIDENTIARY HEARING THE COURT CONCLUDES THAT THE ACTION IS NOT SUPPORTED BY SUBSTANTIAL EVIDENCE, IS CONTRARY TO LAW, IS ARBITRARY AND CAPRICIOUS OR IS AN ABUSE OF DISCRETION. / G. THIS SECTION DOES NOT APPLY TO ANY AGENCY ACTION BY AN AGENCY THAT IS CREATED PURSUANT TO ARTICLE XV, CONSTITUTION OF ARIZONA.» (énfasis del propio texto, ver: https://apps.azleg.gov/BillStatus/ GetDocumentPdf/458044)

174 A este respecto, la nota 4 de la decision mayoritaria de Negusie v. Holder [555 U.S. 511 (2009)], trata el tema de una marea particular por Justice Scalia.

N. ${ }^{\circ} 104$, enero-abril 2019, págs 257-291 


\section{La «presidencia imperial» a la luz del constitucionalismo}

Hoy en día, denominar al Presidente de los EUA como Emperator no resulta hiperbólico. Desde finales del siglo XVIII, la doctrina del hombre providencial sustentó, filosóficamente, la aparición de hombres como Napoleón Bonaparte, de ahí parece surgir la fascinación por la personalidad del Presidente ${ }^{175}$. Dicho ideal guío a ciertos individuos que ocuparon la Presidencia ${ }^{176}$, o bien, permitió que fueran juzgados como débiles quienes no mostraban dominantes ${ }^{177}$. Por ende, el poder ejecutivo y sus poderes adquiridos han determinado que los EUA sea hoy en día una potencia mundial; sus presidentes llevaron este país a entrar en guerras y ganarlas ${ }^{178}$, a superar crisis económicas ${ }^{179}$ y expandir su territorio, comprando de Alaska en $1867^{180} \mathrm{o}$ entrando en el juego geopolítico de la guerra fría ${ }^{181}$, por ejemplo.

Sin embargo, hay que diferenciar entre el fenómeno institucional (i.e. la concentración de poderes el Presidente) y la personalidad individual de quien ocupa la primera magistratura civil ${ }^{182}$. La necesidad de desligarlos permite comprender mejor que el freno más efectivo al poder del ejecutivo es el propio carácter, talante o personalidad del Presidente. No obstante, este factor, si bien es determinante es difícil de medir. Por el contrario, aquello que sí es tangible es el número de decisiones tomadas para satisfacer sus deseos como policymakers. Esto se logró por medio de las órdenes ejecutivas, su uso y su abuso ${ }^{183}$.

175 Twombly, J. (2013). The Progression of the American Presidency. Individuals, Empire, and Change (1st ed.), New York, Palgrave Macmillan. https://doi.org/10.1057/9781137300546

176 Zoller, E. (2011). Histoire du gouvernement présidentiel aux États-Unis, Paris, Dalloz

177 Greenstein, F. I. (2010). «The Policy-Driven Leadership of James K. Polk: Making the Most of a Weak Presidency». Presidential Studies Quarterly, 40(4), 725-733. https://doi. org/10.1111/j.1741-5705.2010.03808.x

178 Burns, K. J. (2017). «The Law: A Constitutionalist's Defense of Prerogative: Taft's Our Chief Magistrate and His Powers». Presidential Studies Quarterly, 47(2), 336-353. https://doi.org/10.1111/ psq. 12371

179 Zelizer, J. E. (2000). «The Forgotten Legacy of the New Deal: Fiscal Conservatism and the Roosevelt Administration, 1933-1938». Presidential Studies Quarterly, 30(2), 332-359. https://doi. org/10.1111/j.0360-4918.2000.00115.x

${ }^{180}$ Cunha, S. F. (2003). «Alaska», en Page, M. E. \& Sonnenburg, P. M. (Eds.), Colonialism : an international social, cultural, and political encyclopedia, Santa Bárbara, ABC-CLIO, 9-10

181 Tuathail, G. Ó., \& Agnew, J. (1992). «Geopolitics and discourse: Practical geopolitical reasoning in American foreign policy». Political Geography, 11(2), 190-204. https://doi. org/10.1016/0962-6298(92)90048-X

182 Twombly, J. (2013). The Progression of the American Presidency. Individuals, Empire, and Change (1st ed.), New York, Palgrave Macmillan. https://doi.org/10.1057/9781137300546

183 Vermeule, A. (2016). Law's Abnegation. From Law's Empire to the Administrative State (1st ed.), Cambridge, Harvard University Press. 
Tabla 2. Órdenes ejecutivas

\begin{tabular}{|l|c|c|c|}
\hline \multicolumn{1}{|c|}{ Presidente } & Periodo & $\begin{array}{c}\text { Número de órdenes } \\
\text { ejecutivas }\end{array}$ & $\begin{array}{c}\text { Promedio de órdenes ejecutivas } \\
\text { por año }\end{array}$ \\
\hline Donald J. Trump & $2017-2018$ & 77 & $54.35^{185}$ \\
\hline Barack Obama & $2009-2017$ & 276 & 34.5 \\
\hline George W. Bush & $2001-2009$ & 291 & 36.4 \\
\hline William J. Clinton & $1993-2001$ & 364 & 45.5 \\
\hline George Bush & $1989-1993$ & 166 & 41.5 \\
\hline Ronald Reagan & $1981-1989$ & 381 & 40 \\
\hline Jimmy Carter & $1977-1981$ & 320 & 42.3 \\
\hline Gerald R. Ford & $1974-1977$ & 169 & 57.7 \\
\hline Richard Nixon & $1969-1974$ & 346 & 46.2 \\
\hline Lyndon Johnson & $1963-1969$ & 324 & 41.3 \\
\hline John F. Kennedy & $1961-1963$ & 124 & 60.8 \\
\hline Dwight Einsenhower & $1953-1961$ & 486 & 112 \\
\hline Harry Truman & $1945-1953$ & 3.728 & 310.6 \\
\hline Franklind Roosevelt & $1933-1945$ & & 466 \\
\hline
\end{tabular}

Fuente: Archivo de los EEUU ${ }^{184}$ : Elaboración propia.

En términos generales, la expedición masiva de órdenes ejecutivas es una constante en el mandato presidencial en los EUA (Tabla 2). Por el contrario, en términos particulares el mensaje debe ser analizado con cuidado para poder hablar de un aporte a la discusión sobre la «presidencia imperial». El cuadro muestra que desde 1930 y hasta los años 80, los Presidentes han tenido una gran actividad en materia de órdenes ejecutivas. Aquellos mandatarios cuyo periodo constitucional fue marcado por la segunda postguerra (i.e. Franklind Roosevelt, Harry Truman, Dwight Einsenhower), tienen el promedio más alto de órdenes ejecutivas. Por su parte, el resto de los presidentes del periodo recientemente señalado (Ronald Reagan y Richard Nixon) — marcados por la Guerra Fría — se sirvieron de un número bas-

${ }^{184}$ Fecha de la consulta junio 25 de 2018: https://www.archives.gov/federal-register/executiveorders/disposition

185 Debe tenerse en cuenta que el 54.35 de órdenes ejecutivas por año se obtiene de sumar 55 órdenes expedidas por Trump en el año 2017 y 22 órdenes expedidas durante el 2018 (hasta el 25 de junio), dividirlas por el número de meses que lleva en el mandato (17) y multiplicarlo por 12. 
tante alto de órdenes ejecutivas, pero sin superar a sus predecesores de la primera mitad del siglo xx. Finalmente, cabe resaltar otra «protuberancia» que el cuadro permite apreciar. Es el hecho de que los últimos dos Presidentes con mandato concluido (Barack Obama y Bush Jr.) tienen un número de órdenes ejecutivas que tiende a la baja. Bush expidió 291 frente a Obama con 15 menos, para un total de 276 órdenes. El primero tiene un promedio de 36.5 órdenes por año y el segundo 34.5. En el caso de Donald Trump es evidente un repunte en el uso de este tipo de normas, pues en 17 meses ha expedido 77 órdenes ejecutivas para un promedio de 54.35 por año.

La descripción del aumento o declive del número de órdenes ejecutivas resulta menos reveladora que su análisis constitucionalista normativista, desde la estructura misma de la Constitución y el principio de separación de poderes.

En primer lugar, desde la crítica normativista puede afirmarse que una Constitución es una norma eminentemente política, pero una norma al fin y al cabo ${ }^{186}$. Este comentario pragmático, no puede ser considerado un verdadero argumento, pero la teoría de la Constitución normativa sí debe tenerse en cuenta. En concordancia con lo anterior, si observamos el elevado número de órdenes ejecutivas; si miramos, igualmente, que las razones para tomarlas están ligadas a la necesidad social o económica, por ejemplo; y si conocemos, principalmente, el hecho de que las órdenes ejecutivas no están definidas en la Constitución cuando habla del ejecutivo federal; entonces, puede concluirse que resulta difícil justificar su elevado número.

En segundo lugar, desde una crítica constitucionalista formulada a partir del principio de la separación de poderes, resulta pertinente afirmar que el creciente número de órdenes ejecutivas es consecuencia de una desmesurada concentración de $\operatorname{poder}^{187}$. El Artículo I de la Constitución de 1787 encarna la mecánica ideada por los Framers para la formación de la ley ${ }^{188}$; el Presidente no interviene más que tangencialmente a través de las recomendaciones al Congreso fundadas en el Artículo II, Sección 3, Cláusula 2. En efecto, en lo profundo del andamiaje constitucional, la contradicción entre el legado de John Locke ${ }^{189}$ y la «presidencia imperial» resulta evidente $^{190}$. El insipiente estado de bienestar estadounidense también ha contribuido

186 Pasquino, P. (1998). Sieyès et l'invention de la Constitution en France (1st ed.), Paris, Éditions Odile $\mathrm{Jacob}$.

187 Rudalevige, A. (2012). «The Contemporary Presidency: Executive Orders and Presidential Unilateralism». Presidential Studies Quarterly, 42(1), 138-160. https://doi.org/10.1111/j.1741-5705.2012.03945.x

188 Schlesinger, A. M. (2004). War and the American presidency, London, W.W. Norton \& Company, Inc.

189 Locke, J. (1824). Two Treatises of Gouvernment. The Works of John Locke in Nine Volumes (12th ed., Vol. 4), London, Rivington.

190 Si la propuesta de El Segundo Tratado del Gobierno Civil es el fundamento del derecho constitucional contemporáneo, el incremento de las prerrogativas y poderes del ejecutivo pone en entredicho la eficacia de la separación de poderes. Ver: Locke, J. (1824). Two Treatises of Gouvernment. The Works of John Locke in Nine Volumes (12th ed., Vol. 4), London, Rivington, pp. 383-485. 
para acrecentar el protagonismo de algunos mandatarios como fueron los casos de Roosevelt y su new deal y Obama y su Obamacare. ${ }^{191}$

Para mejorar la situación, los otros poderes públicos tienen varios mecanismos y para restablecer el equilibrio perdido. El Congreso puede, en primer lugar, derogar las órdenes ejecutivas a través de sus leyes; sin embargo, este control suele ser ineficaz cuando el partido del presidente tiene las mayorías. Además, el trámite para la creación de la ley fue diseñado para ser complejo y demorado tal y como nos lo ilustra la anécdota del «senatorial saucer» que recrea un desayuno entre Washington y Thomas Jefferson ${ }^{192}$. No obstante, si bien la ley debería ser un límite, puede suceder también que esta pueda convertirse en su inverso toda vez que ambas cámaras del Congreso están sujetas a los avatares de la política, y con ello, a las mayorías; una vez coaligadas con el Presidente, de ninguna manera puede hablarse de la ley como un freno efectivo.

En segundo lugar, la Cámara de Representantes puede acusar al Presidente ante el Senado en el llamado Impeachment; el fundamento son las Secciones 3.6 y 3.7, así como la Sección 2.5, del Artículo I de la Constitución de 1787. Como ocurrió con Nixon por el escándalo de Watergate ${ }^{193}$, por ejemplo, puede declararse responsable al Presidente con fundamento en el Artículo II, Sección 4.

Por último, es necesario acudir al poder judicial, pues corresponde a la función judicial ${ }^{194}$ la tarea de impedir o — en lo posible_- diezmar los excesos del ejecutivo. Esto se logra, al oponerse a las órdenes ejecutivas por la vía del Judicial Review. En efecto, el propio espíritu contra-mayoritario de un poder genuinamente aristocrático parecería la salida para contrarrestar los deseos de un líder popular, elegido por las mayorías y que cuenta con el respaldo de cámaras del legislativo. Pero no hay que olvidar que la Corte Suprema, cabeza el poder judicial, declaró la constitucionalidad de un gran número de las órdenes ejecutivas expedidas por el Presidente Franklin D. Roosevelt. Un ejemplo de la posible impotencia del judicial frente a un ejecutivo popular, es la precita decisión Korematsu ${ }^{195}$ y permitió la de discriminación abierta

191 En ese sentido ya García Pelayo refiriéndose al Estado Social de Derecho había advertido como los poderes ejecutivo y legislativo modifican sus límites tradicionales para para garantizar derechos, en los siguientes términos: «iv) por ser un Estado de prestaciones, de modo que a los preceptos constitucionales que limitan su actividad añade otros que le fijan objetivos para su acción legislativa y administrativa, con lo cual la Grundkompetenz, cuyos límites han sido establecidos por los primeros, recibe unos objetivos definidos por los segundos.» García-Pelayo, M. (1981) Las transformaciones del Estado contemporáneo, Madrid: Alianza Editorial, pp. 92-104.

192 Conway, M. D. (2008) Chapters of History Disclosed in the Life and Papers of Edmund Randolph. Read Books, p. 91.

193 Zoller, E. (1999a). De Nixon à Clinton: malentendus juridiques transatlantiques (1st ed.), Paris, PUF

${ }^{194}$ El Impeachment y la actividad de la Corte Suprema de Justicia son manifestaciones de la misma función, ver: Troper, M. (1980). La separation des pouvoirs et l'histoire constitutionnelle francaise (1st ed.), Paris, LGDJ-Montchrestien, pp. 43-46.

195 U.S. Supreme Court, Korematsu v. United States, 323 U.S. 214. 
de ciudadanos americanos de ascendencia japonesa durante la guerra. No está de más recordar la indiferencia de la Corte Suprema de Justicia frente a las prisiones donde existe suspensión de los derechos humanos — por lo menos hasta la decisión Boumediene vs. Bush ${ }^{196}$ — como fueron los casos de Guantanamo y Abu Graib, mientras que en 2017, en contrapartida, se abría la posibilidad de utilizar el ATS de 1789 con el caso Jesner vs. Arab Bank ${ }^{197}$.

En suma, los frenos y contrapesos respaldan la separación de poderes para que cada una de las ramas del poder público cuente con mecanismos necesarios para mantener a raya a sus homólogos ${ }^{198}$ y es, justamente, por esto resulta desconsolador que algo tan alejado de lo institucional como la personalidad de un Presidente pueda considerarse como el primer freno a su poder. Es por eso que la fineza e inteligencia con que fue creada la Constitución de 1787 ata la fragilidad de los límites institucionales del poder al juramento de la Cláusula 8 (Artículo II, Sección 1). La fórmula que sigue a continuación impone el deber de sobreponer los intereses de la nación a los suyos propios: "Juro solemnemente que serviré fielmente el cargo de Presidente de los Estados Unidos, y que haré todo lo posible por preservar, proteger y defender la Constitución de los Estados Unidos.»

Frente a todo lo anterior, puede postularse que el gobierno representativo es el único remedio contra estas maneras en que los poderes públicos se ven indefensos frente al ejecutivo. La mejor forma de impedir que un emperador —un déspota ilustrado o un ignoramus - entre a la Casa Blanca, es cerrarle la puerta por las vías democráticas. Cuando la Constitución de la Unión, en su preámbulo, comienza a con las palabras We, the People, hace una invitación abierta a cada individuo y cada Estado federado a hacer uso de la I Enmienda y de libertades como la libertad de prensa y con esto menguar la estrella de los tiranos bien amados o de líderes facciosos.

En los albores de la Unión, es bien conocida el intercambio de palabras entre Benjamin Franklin y Powel, quienes se dicen: «Well, Doctor — dice Powel refiriéndose al recién concluida la Convención de Filadelfia de 1787- what have we got, a republic or a monarchy?" A lo que responde Franklin: "Without hesitation, a republic, if you can keep it.» ${ }^{199}$. La anécdota genera una duda: ¿qué puede hacerse contra un líder faccioso? A lo que cabe responder como Franklin: oponerle la moderación inherente a la república mientras se pueda.

196 U.S. Supreme Court, Boumediene v. Bush, 553 U.S. 723, 2008.

197 Felipe Calderón-Valencia, Pilar Valencia-DeLara, and Manuela Escobar-Sierra, «Current Status of The Discussion on Human Resources Management: An Alternative View From Corporate Social Responsibility and Law», in ICLEL 17 Conference Proceeding Book - 3rd International Conference on Lifelong, ed. by Paulo Alberto da Silva Pereira, Osman Titrek, and Gozde Sezen-Gultekin, 1st edn (Sakarya: ICLEL Conferences, 2017), pp. 747-60; United States Court of Appeals for the Second Circuit, Jesner v. Arab Bank, PLC, 2017, pp. 16-499; U.S. Supreme Court, Jesner v. Arab Bank, No. 13-3605 (2d Cir. 2015), 2015.

198 Zoller, E. (1999b). Droit constitutionnel (2nd ed.), Paris, PUF.

199 «Papers of Dr. James McHenry on the Federal Convention of 1787» (1906). The American Historical Review, 11(3), 595-624 «https://doi.org/DOI: 10.2307/1836024» 


\section{CONCLUSIÓN}

La «presidencia imperial» es una dicotomía. Por un lado, se postula como algo no querido por el diseño constitucional propuesto por los Padres Fundadores o Framers en la Asamblea Constitucional de 1787. Pero, por otro lado, es una consecuencia no evitada de un sistema que permite actuar a las ramas del poder público en la medida en que el texto constitucional no imponga una prohibición expresa.

En la medida que los estados cedían competencias en favor de la Unión y que los poderes legislativo y judicial voluntariamente se relegaban en favor de la administración en general y el ejecutivo en particular, estas circunstancias fueron aprovechadas por líderes fuertes, carismáticos o simplemente voluntariosos, que al hacerse elegir en la Presidencia del gobierno federal, no dudaron en expandir los poderes y prerrogativas para proyectar la institución sobre sus deseos o planes de gobierno. Para hacerlo efectivo, se valieron de la producción normativa unilateral encarnada por las llamadas órdenes ejecutivas, capaces de producir los mismos efectos de una ley sobre las autoridades y organismos bajo el control de la rama ejecutiva.

El auge de las órdenes ejecutivas parece estar más lejos de la institucionalidad de los EUA, pues su estabilidad depende de la personalidad de quien ocupa la Presidencia, pero esto no hace de ella un instrumento imperial. De ahí, por ejemplo, que el número de órdenes ejecutivas parezca haberse diezmado con el fin del siglo xx, lo que coincide con el aumento de la influencia del Presidente sobre las AAF. Pese a esto, la razón de ser de estas normas tiene tanto de azarosa como de racional y necesario (crisis sociales, económicas y guerras), aunque el Jefe de Estado de la Unión haya hecho uso de ellas por fuera de estas circunstancias.

No solo las órdenes ejecutivas y su elevado número pueden explicar la consolidación de la «presidencia imperial». Los poderes del ejecutivo federal se desbordaron, igualmente, por su injerencia sobre las AAF, cuyas facultades no están consagradas en la constitución, pero sí en el llamado APA de 1946. Primero el Congreso y luego la Corte Suprema permitieron la extensión de sus poderes, que son —en principioun organismo para ampliar los poderes del Presidente. En efecto, a través de sus órdenes puede controlarlos, pero en vista de que son considerados el cuarto poder del gobierno federal, su independencia también puede afectar al propio ejecutivo, por la misma naturaleza del check and balances.

Entonces, para responder a la pregunta ¿qué tipo de límites, institucionales y reales tiene la Presidencia de los EUA?, puede afirmarse que estos son de ambos tipos, pero, pese a esto, la «presidencia imperial» se opone a la república moderada; pese a que el sueño de los Padres Fundadores parece haberse difuminado, su sueño es ahora de los vivos, de otros hombres con otras ambiciones, pero igualmente acosados por la mecánica que montaron los autores del Federalista. 
Title:

The «imperial presidency» and its evolution in the constitutional structure of the United States America

\title{
Summary:
}

INTRODUCTION. II. THE SPIRIT AND ITS STRUCTURE OF THE AMERICAN CONSTITUTION OF 1787. 1. An oxymoron: the weakest power. 2. The separation of powers and the check and balances system. 3. Hamilton, Madison y Marshall: defenders of the Constitution of 1787. II. THE IMPERIAL PRESIDENCY: A THREAT TO THE CONSTITUTIONAL STRUCTURE. 1. Birth of the «imperial presidency». 2. Consolidation of the «imperial presidency». 3. Fullness of the «imperial presidency». 4. The «imperial presidency» in a constitutionalism point of view. CONCLUSION.

\begin{abstract}
:
This article analyzes «Imperial Presidency» in US Constitutional Law from a historical and institutional perspective. This is firstly made from a philosophical foundation of American constitutionalism and secondly from an evolution of the Presidential government. These two parts try to answer the question about the limits of the Federal presidency. It should be noted that these are not enough, because the executive orders promote the President's role, allowing the US to become a powerful country. The conclusion of this work that the «imperial presidency» is opposed to the moderate republic of the Founding Fathers; the blur limits of the executive department always adjust to the political power facts and situations.
\end{abstract}

\section{Key words:}

Imperial Presidency, US. Constitutional Law, executive orders, checks and balances.

\section{Resumen:}

Este artículo analiza el concepto de «presidencia imperial» en el derecho constitucional de los Estados Unidos de América desde una perspectiva histórico-institucional. Este análisis se plantea, primero, desde los fundamentos jus-filosóficos del constitucionalismo norteamericano y, segundo, desde el devenir del gobierno presidencial. La bipartición responde la pregunta sobre los límites, institucionales y reales tiene la Presidencia. Se observa que estos no son suficientes, pues las órdenes ejecutivas promueven el protagonismo del Presidente, permitiendo a aquel país transformarse en una gran potencia. Se concluye que la 
«presidencia imperial» se opone a la república moderada de los Padres Fundadores; la desestructuración de los límites al poder ejecutivo siempre se ajusta a los hechos y avatares del poder político.

Palabras clave:

Presidencia imperial, Derecho Constitucional Estadounidense, órdenes ejecutivas, frenos y contrapesos. 